\title{
Índice de desenvolvimento rural dos municípios paranaenses: determinantes e hierarquização ${ }^{1}$
}

\author{
Cármem Ozana de Melo* \\ José Luiz Parré**
}

Resumo: A implementação do modelo produtivista na agricultura brasileira provocou importantes alterações no espaço rural, afetando o seu desenvolvimento. O setor agrícola paranaense inseriu-se nesse processo, apresentando mudanças significativas na sua estrutura produtiva, com reflexos econômicos e sociais importantes no meio rural. Neste sentido, este trabalho objetivou mensurar o índice de desenvolvimento rural dos municípios paranaenses, identificando os fatores determinantes. Os resultados mostraram que, numa escala de zero a 100, o índice médio de desenvolvimento rural situou-se em 43,63, resultando num total de 179 municípios (44,86\%) acima deste valor e 220 municípios $(55,14 \%$ ) abaixo deste índice. A ordenação de acordo com o grau de desenvolvimento evidenciou que mais da metade dos municípios se encontra nos níveis baixo, muito baixo e muitíssimo baixo de desenvolvimento rural sugerindo a necessidade de medidas no sentido de minimizar os efeitos gerados pelos aspectos que devem ser trabalhados de forma mais intensa, no sentido de melhorar a vida no campo e, por conseguinte, a situação dos municípios.

\footnotetext{
* Mestre em Economia. Professora do Curso de Economia da Universidade Estadual do Oeste do Paraná. carozmelo@bol.com.br

** Doutor em Economia Aplicada. Professor Adjunto do Departamento de Economia e do Programa de Mestrado em Economia da Universidade Estadual de Maringá. jlparre@uem.br

${ }^{1}$ Trabalho baseado na dissertação de mestrado da autora, defendida em fevereiro de 2006, junto ao Programa de Mestrado em Economia da Universidade Estadual de Maringá, sob a orientação do co-autor deste artigo.
} 
Palavras-chave: desenvolvimento rural, estatística multivariada, Paraná.

\section{Classificação JEL: 018}

Abstract: The introduction of the productivity gains model in the Brazilian agriculture has caused important changes in the rural environment, affecting its development. The agricultural sector in Paraná is part of this process and in this state, also, there have been significant shifts in the structure of production, which have had an indirect influence both economically and socially in the countryside. This essay, therefore, aims to measure the rural development rate in the cities of Parana and identify the determining factors. The results have shown that, in a scale of 0 to 100, the average rural development rate is 43,63. 179 cities (44,86\%) present rates above the mark mentioned and 220 (55,41\%) are under this mark. By organizing the cities according to the development degree it was evident that more than half of the cities in the state have had low, very low or extremely low levels of rural development, a situation that calls for actions that aim to minimize the effects of the aspects which must be intensely worked on in order to improve life in the country and as a consequence, life in the city.

Key words: rural development, multivariate statistics, Paraná.

JEL Classification: 018

\section{Introdução}

A análise do desenvolvimento não é simples, pois trata de um fenômeno que envolve uma série de transformações tecnológicas, sociais, distributivas e econômicas. Abrange, pois, um conjunto de indicadores demográficos, econômicos, sociais e ambientais sendo, portanto, um conceito complexo e multissetorial.

Contudo, na década de 1950, os países subdesenvolvidos deram especial atenção à idealização de planos que limitaram-se, basicamente, a um processo de industrialização intensiva, que se configurava como sinônimo de desenvolvimento econômico. 
Neste contexto, tradicionalmente, o setor agrícola configurava-se como tendo certas funções a desempenhar com o objetivo de dar suporte ao processo de industrialização. A agricultura e, por extensão, o setor rural deveria liberar mão-de-obra para o setor industrial, fornecer produtos alimentícios e matérias-primas, transferir capital, ampliar a disponibilidade de divisas e demandar produtos industrializados. Dessa forma, a agricultura necessariamente expandiria sua inter-relação com o setor urbano-industrial. Nesta concepção, o desenvolvimento agrícola era interpretado como um passo para a realização do desenvolvimento industrial e conseqüente crescimento econômico.

E esta foi a opção adotada no caso brasileiro, ao implementar o modelo preconizado pelos princípios da "revolução verde", o qual pressupunha que o desenvolvimento agrícola (visão da agricultura como um setor econômico distinto) levaria ao desenvolvimento rural.

Assim, as mudanças que se processaram na agricultura brasileira, principalmente a partir do final da década de 1960, caracterizaram uma redefinição das relações entre a agricultura e a indústria, dando origem a um novo padrão de produção agrícola. A reestruturação do setor agrícola, com forte intervenção estatal, privilegiou, em seu pacote tecnológico, o uso de sementes selecionadas e de insumos químicos, irrigação, mecanização agrícola e variedades genéticas das culturas que mais se adaptaram ao ambiente das regiões brasileiras.

Entretanto, os impactos não foram uniformes em todas as regiões do país e nem em todos os estratos de produtores: os incentivos privilegiaram o grande capital agrícola, enquanto estimulavam a expropriação e a expulsão do homem do campo; intensificou-se a concentração fundiária; foram privilegiadas as regiões mais desenvolvidas e os grandes produtores rurais, aumentando ainda mais a acumulação de capital nesse segmento.

Aliado a isso, o setor rural deixou de ser um espaço exclusivamente agrícola. Algumas atividades ligadas à instalação de indústrias, lazer, comunicações, desenvolvidas na área rural ou em áreas próximas, passaram a ter uma relação estreita com a atividade agrícola, de modo que um contingente significativo de pessoas, mesmo vivendo na zona rural, passou a exercer atividades não tipicamente agrícolas.

Neste contexto, de acordo com Veiga (2000), não existe o desen- 
volvimento rural como fenômeno concreto e separado do desenvolvimento urbano. De acordo com Kageyama (2004), apesar de ser controversa a definição de rural há, contudo, um certo consenso entre os seguintes pontos: rural não é sinônimo de e nem tem exclusividade sobre o agrícola; o rural é multissetorial (pluriatividade) e multifuncional (função produtiva, ambiental, ecológica, social); as áreas rurais têm densidade populacional relativamente baixa; não há um isolamento absoluto entre os espaços rurais e as áreas urbanas. O 'redescobrimento' do desenvolvimento rural se deu em função da necessidade de reorientação do protecionismo da Política Agrícola Européia (PAC), que reconheceu, de um lado, os problemas criados pela agricultura intensiva e, de outro, a multifuncionalidade do espaço rural.

Contudo, segundo Mattei (s/d), com raras exceções, ainda prevalece como estratégia para combater a pobreza rural e elevar os índices de emprego rural, no Brasil, a visão econômica neoclássica. Neste sentido, as políticas públicas governamentais, em sua maioria, ainda privilegiam, tanto na esfera federal quanto nas esferas estaduais, o desenvolvimento agrícola como se este fosse o único caminho possível para se atingir o desenvolvimento rural. O mesmo autor aponta que esse processo gera diversidade regional e intra-regional, ocorrendo regiões com elevados índices de modernização e outras extremamente retardatárias, além de ter acentuado as desigualdades sociais.

Com isso, Souza (2000) argumenta sobre a necessidade de se estudar como articular uma política de desenvolvimento rural que vitalize o tecido social do meio rural e propicie um grau de atividade a fim de manter a população com níveis compatíveis de ocupação e de renda e que promova o bem-estar no mesmo nível que o das cidades.

No Paraná, as transformações ocorridas na agricultura brasileira também puderam ser percebidas. O setor agrícola paranaense inseriu-se no processo de modernização, apresentando alterações significativas na sua estrutura produtiva. As inovações tecnológicas foram responsáveis pela mudança na pauta da produção, tendo como objetivo aprimorar sua competitividade, colocando o estado em destaque no âmbito nacional ao apresentar resultados expressivos de sua agropecuária.

As bases da atual estrutura produtiva paranaense foram iniciadas nos 
anos 70, quando foram criadas condições para prosperar uma agricultura em padrões capitalistas, dando origem ao agronegócio no estado.

Já os anos 80 têm sido vistos como uma década marcada por crises e instabilidade econômica, as quais impuseram limites ao desempenho e crescimento da estrutura produtiva brasileira e paranaense. Entretanto, a recessão ocorrida nos primeiros anos dessa década não causou grandes prejuízos à economia do Paraná em função do desempenho favorável da agropecuária e de alguns ramos industriais, como o de alimentos e a indústria química, não obstante a profunda crise da indústria da construção civil. Em termos setoriais, a agropecuária, apesar da grande instabilidade das políticas econômicas e das profundas alterações dirigidas a este setor, não sofreu danos significativos. Contudo, desde a segunda metade da década de 1980, as mudanças da estrutura produtiva da agricultura paranaense vêm se verificando de forma menos intensa que a observada na década de 1970. Tais mudanças implicaram em dois aspectos: modificações e diversificação na pauta de produção e a incorporação de novas tecnologias de modo a compensar o esgotamento da fronteira agrícola.

Na década de 1990, as mudanças verificadas na atividade agrícola do estado na década anterior se tornam mais rápidas em decorrência da abertura comercial e da valorização do câmbio, com a finalidade de enfrentar a concorrência internacional. Intensificou-se o deslocamento regional da produção agrícola em direção às regiões que oferecem condições propícias para o desenvolvimento de sistemas produtivos mais competitivos.

Há, contudo, que se ressaltar que a exemplo do ocorrido em todo o país, tais mudanças foram acompanhadas por importantes reflexos no meio rural paranaense. Neste aspecto, Pereira (1987) aponta para conseqüências como a concentração no acesso à terra, a modificação no nível de emprego e a redução na oferta de alimentos básicos. Também Souza (2000) afirma que, de forma geral, as transformações na base técnica de produção da agricultura paranaense modificaram profundamente a organização social rural e acarretaram impactos, citando alterações na estrutura fundiária, na evolução das ocupações agrícolas e nas relações de trabalho no campo, o impulso às organizações em defesa dos agricultores - as cooperativas, e, finalmente, 
a questão da migração e urbanização. Estudo realizado por Boni e Cunha (2002) acerca da evolução da estrutura fundiária no Paraná, no período de 1970 a 1995/96, permite verificar o aumento da concentração da propriedade da terra no estado e aponta como causa o processo de modernização da agropecuária que teve, por sua vez, reflexos no movimento migratório.

Assim, mesmo reconhecendo todo o processo como avanço no sentido positivo, ao aumentar a eficiência da agricultura e do agronegócio no estado, é preciso considerar que esse movimento representou também um sentido negativo, na direção das disparidades.

Dessa forma, conhecer como se encontra o setor rural em termos de desenvolvimento se faz importante e, para isso, a obtenção de medidas sintéticas pode contribuir no sentido de permitir análises, avaliações de programas e de intervenções, servindo como ponto de partida para a discussão das heterogeneidades e de ações que possam ser seguidas em busca do desenvolvimento rural. Diante disso, este trabalho tem por objetivo mensurar o índice de desenvolvimento rural dos municípios paranaenses, identificando os fatores determinantes.

\section{Metodologia}

Para o presente estudo, dado o caráter multidimensional do conceito de desenvolvimento, utilizou-se a técnica da análise estatística multivariada, mais especificamente, a análise fatorial.

Podem ser citados vários trabalhos que empregaram tal técnica. Hoffmann (1992) elaborou estudo sobre a dinâmica da modernização da agricultura para 157 microrregiões homogêneas de oito estados brasileiros. Empregando as técnicas de análise fatorial e de agrupamento, Ferreira Júnior; Baptista e Lima (2003), realizaram estudo acerca da modernização agropecuária nas microrregiões do Estado de Minas Gerais. No mesmo sentido, a fim de mostrar que o desenvolvimento da agricultura ocorreu de forma diferenciada nos municípios paranaenses, Rezende e Parré (2004) utilizaram duas técnicas de análise multivariada: a análise fatorial e a de cluster. O método da análise fatorial também se encontra no trabalho desenvolvido por Rezende e Parré (2003), cujo objetivo principal foi o de detectar o grau de de- 
senvolvimento do setor agrícola dos municípios paranaenses durante a década de 1990. Aplicando-se dois métodos estatísticos de análise multivariada: análise fatorial e análise de cluster, Llanillo; Pellini e Doretto (2004) realizaram estudo a fim de identificar territórios rurais no Estado do Paraná, constituídos por municípios com características relativamente homogêneas quanto à sua estrutura agrária. Podem-se ainda citar outros trabalhos que empregaram a análise fatorial: Silva e Fernandes (2004), com o objetivo de determinar o grau de modernização agrícola para os municípios da Região Norte; Zambrano e Pinto (2004), a fim de mostrar as diferenças econômicas e sociais da população dos municípios mato-grossenses; Mata et al. (2004), com o objetivo de definir o padrão de desenvolvimento dos municípios do Estado da Bahia; Rosado, Rossato e Lima (2005), a fim de estudar a hierarquização e o desenvolvimento sócio-econômico das microrregiões de Minas Gerais.

\subsection{A análise fatorial}

A análise fatorial tem como princípio básico a redução do número original de variáveis, por meio da extração de fatores independentes, de tal forma que estes fatores possam explicar, de forma simples e reduzida, as variáveis originais. De acordo com Rezende e Parré (2004), o método de análise fatorial é uma técnica estatística multivariada usada para sintetizar as informações contidas na matriz de dados original num número reduzido de padrões de características (fatores) relativos a um conjunto de variáveis correlacionadas entre si. Em suma, esta técnica permite extrair um número reduzido de fatores, que são combinações lineares das variáveis originais, perdendo o mínimo de informações. Este método de análise é muito empregado, como aponta Haddad (1989) para juntar regiões ou locais de acordo com a similaridade de seus perfis; e agrupar variáveis para delinear padrões de variações nas características. Estes agrupamentos definem um conjunto de fatores que permitem identificar o estágio de desenvolvimento econômico, social, urbano e outros tipos de desenvolvimento de um determinado local ou região. A análise fatorial pode ser realizada através do método de componentes principais, que 
faz com que o primeiro fator contenha o maior percentual de explicação da variância total das variáveis da amostra; o segundo fator contenha o segundo maior percentual, e assim por diante (Ferreira Junior, Baptista e Lima, 2003).

O método de análise fatorial pode ser expresso na forma matemática através de uma combinação linear entre as variáveis $\left(\mathrm{X}_{\mathrm{i}}\right)$ e $\mathrm{K}$ fatores comuns (F)

$$
X_{i}=A_{i 1} F_{1}+A_{i 2} F_{2}+\ldots+A_{i k} F_{k}+U_{i}+E_{i}
$$

Onde: $A_{i k}$. Cargas fatoriais, usadas para combinar linearmente os fatores comuns.

$\mathrm{F}_{1}, \mathrm{~F}_{2, \ldots,} \mathrm{F}_{\mathrm{k}}$ - Fatores comuns

$\mathrm{U}_{\mathrm{i}}$ - Fator único

$\mathrm{E}_{\mathrm{i}}$ - Fator de erro

As cargas fatoriais indicam a intensidade das relações entre as variáveis normalizadas $\mathrm{X}_{\mathrm{i}}$ e os fatores. Quanto maior uma carga fatorial, mais associada com o fator se encontra a variável. A variância comum $\mathrm{h}_{\mathrm{i}}{ }^{2}$, ou comunalidade, representa quanto da variância total de $\mathrm{X}_{\mathrm{i}}$ é reproduzida pelos fatores comuns, sendo calculada a partir do somatório ao quadrado das cargas fatoriais. A variância única $U_{i}$ é a parte da variância total que não se associa com a variância das outras variáveis. $\mathrm{O}$ termo $\mathrm{E}_{\mathrm{i}}$ representa o erro de observação, de mensuração ou de especificação do modelo.

A medida denominada de Eigenvalue, ou raiz característica, expressa a variância total do modelo explicada por cada fator. De acordo com Ferreira Junior, Baptista e Lima (2003), na determinação do número de fatores necessários para representar o conjunto de dados, usualmente consideram-se apenas os fatores cuja raiz característica é maior que a unidade. O seu valor é o somatório dos quadrados das cargas fatoriais de cada variável associada ao fator específico. O eigenvalue divido pelo número de variáveis $\left(\mathrm{X}_{\mathrm{i}}\right)$ determina a proporção da variância total explicada pelo fator.

Para facilitar a interpretação destes fatores é realizada uma rotação ortogonal pelo método varimax, que procura minimizar o número de variáveis fortemente relacionadas com cada fator, permitindo, assim, obter fatores mais facilmente interpretáveis. 
No modelo de análise fatorial, há uma medida de adequação dos dados, o Kaiser-Meyer-Olkin Measure of Sampling Adequacy (KMO). O KMO é a razão da soma dos quadrados das correlações de todas as variáveis dividida por essa mesma soma acrescentada da soma dos quadrados das correlações parciais de todas as variáveis. O KMO é, portanto, um teste que examina o ajuste dos dados, tomando todas as varáveis simultaneamente, e provê uma informação sintética sobre os dados e seu valor varia entre zero e um. Para a interpretação do KMO considera-se: 0,90-1,00: excelente; 0,80-0,90: ótimo; 0,70-0,80: bom; 0,60-0,70: regular; 0,50-0,60: ruim; 0,00-0,50: inadequado. Um outro teste, que precede a análise fatorial com vistas à verificação de suas premissas, é o Barlett Test of Sphericity (BTS), que testa a hipótese de que a matriz de correlação é uma matriz identidade, ou seja, que não há correlação entre as variáveis.

Através da utilização do software SPSS (versão 11.5), foram obtidos os fatores e selecionados os que apresentaram valores maior que 1. Identificados os fatores, é feita a estimação do escore fatorial, por meio do método semelhante ao da regressão. O escore para cada observação (município) é resultado da multiplicação do valor (padronizado) das variáveis pelo coeficiente do escore fatorial correspondente, sendo a expressão geral para estimação do j-ésimo fator $F_{j}$ dada por:

$$
F_{j}=W_{j 1} X_{1}+W_{j 2} X_{2}+W_{j 3} X_{3}+\ldots+W_{j p} X_{p}
$$

em que os $W_{j i}$ são os coeficientes dos escores fatoriais e $p$ é o número de variáveis.

Os escores fatoriais de cada fator possuem distribuição normal, com média zero e variância unitária e, desse modo, podem ser utilizadas para indicar a posição relativa de cada observação relativamente ao conceito expresso pelo fator. Assim, a partir da matriz dos escores fatoriais, é possível construir um índice para hierarquizar as observações (Monteiro e Pinheiro, 2004).

A verificação do grau de desenvolvimento de cada município paranaense foi feita através dos escores fatoriais, ou seja, dos va- 
lores dos fatores para cada uma das 399 observações (municípios). Através da fórmula 3, obteve-se o Índice Bruto de Desenvolvimento, por meio do cálculo da média dos fatores (ponderada pela variância) pertencentes a cada observação. Como procedeu-se à análise fatorial pelo método de componentes principais (que faz com que o primeiro fator contenha o maior percentual de explicação da variância total das variáveis da amostra, o segundo fator contenha o segundo maior percentual, e assim por diante), a ponderação pela proporção de explicação da variância total exprime a importância relativa de cada fator. Procedimentos semelhantes podem ser encontrados em Cunha, Lima e Moura (2005); Silva, Melo e Esperancini (2006); Monteiro e Pinheiro (2004) e Melo e Parré (2006).

Há que se acusar que medidas desse tipo podem carregar algum tipo de viés, uma vez que apresentando resultado médio, possa disfarçar algum aspecto específico de determinado município. Contudo, mesmo não permitindo uma medida ideal, estudos neste sentido podem se constituir em um passo para posteriores pesquisas. Ademais, a análise pormenorizada dos valores de cada um dos fatores que compõem o índice (Tabela 4 - Anexo) pode contribuir para focar alguma característica específica.

$$
B=\frac{\sum_{i=1}^{5}\left(w_{i} F_{i}\right)}{\sum_{i=1}^{5} w_{i}}
$$

Sendo: IB = Índice bruto (média ponderada dos escores fatoriais)

$\mathrm{W}_{\mathrm{i}}=$ Proporção da variância explicada por cada fator $\mathrm{F}_{\mathrm{i}}=$ Escores fatoriais

A partir daí, por meio de interpolação, considerando-se o maior valor como 100 e o menor como zero, foi obtido o Índice de Desenvolvimento Rural (IDR) para cada município, atribuindo-se-lhes uma ordenação. Foram considerados com grau de desenvolvimento muitíssimo alto (MMA) aqueles que apresentaram resultados com três desvios-padrão acima da média; muito alto (MA) aqueles com resultados entre dois e três desvios-padrão acima da média; alto (A), aqueles 
com valores entre um e dois desvios-padrão acima da média; médio (M), os que apresentaram resultado entre a média e um desvio-padrão acima da média; baixo (B), aqueles com resultados no intervalo entre a média e um desvio-padrão abaixo da média; muito baixo (MB), os que tiveram resultados no intervalo entre um e dois desvios-padrão abaixo da média e, por último, muitíssimo baixo (MMB), os municípios com resultados dois desvios-padrão abaixo da média.

\subsection{Descrição das variáveis}

A limitação da disponibilidade de dados, de certa forma, inibe abarcar todos os aspectos inerentes ao processo de desenvolvimento. A fim de se mensurar o grau de desenvolvimento do setor rural dos municípios paranaenses, foram selecionadas variáveis que permitissem abranger vários aspectos, a partir das estatísticas disponíveis. Todas as variáveis referem-se ao ano de 2000.

As variáveis selecionadas neste estudo foram: $\mathbf{X}_{1 \text { - }}$ densidade demográfica; $\mathbf{X}_{2}$ - proporção de população rural; $\mathbf{X}_{3}$ - Proporção de pessoas naturais de outros municípios (migrantes); $\mathbf{X}_{4}$ - proporção de domicílios rurais com instalação sanitária; $\mathbf{X}_{5}$ - número de alunos matriculados nos ensinos pré-escolar, fundamental e médio na zona rural; $\mathbf{X}_{6}$ - número de intoxicações por agrotóxico; $\mathbf{X}_{7}$ - consumo de energia elétrica rural $(\mathrm{Mwh}) ; \mathbf{X}_{\mathbf{8}}$ número de consumidores de energia elétrica rural; $\mathbf{X}_{\mathbf{9}}$ número de pessoas ocupadas em atividades agrícolas; $\mathbf{X}_{10}$ produtividade do trabalho na agricultura (VBP/pessoal ocupado); $\mathbf{X}_{11}$ renda municipal agrícola per capita (VBP/população total ); $\mathbf{X}_{12}$ - salário nominal na agropecuária (R\$); $\mathbf{X}_{13}$ - produtividade da terra na agricultura - soja (quantidade produzida/área colhida); $\mathbf{X}_{14}$ - produtividade da terra na agricultura - milho (quantidade produzida/área colhida); $\mathbf{X}_{15}$ - valor dos financiamentos de custeio, investimento e comercialização a produtores e cooperativas agropecuárias (R\$); $\mathbf{X}_{16}$ - número de contratos de financiamentos de custeio, investimento e comercialização a produtores e cooperativas agropecuárias; $\mathbf{X}_{17}$ - área plantada com milho/área plantada total; $\mathbf{X}_{18}$ - área plantada com soja/área plantada total.

Os indicadores de população e migração $\left(\mathrm{X}_{1}\right.$ a $\left.\mathrm{X}_{3}\right)$ procuram medir 
o dinamismo populacional que deveria favorecer o desenvolvimento rural. $\mathrm{O}$ indicador $\mathrm{X}_{4}$ permite abordar em parte a situação dos domicílios rurais, podendo-se observar se as pessoas residentes no meio rural desfrutam de melhor qualidade de vida. Diversos são os estudos sobre desenvolvimento que incluem e concluem sobre a importância da educação para o desenvolvimento. Nesta pesquisa, este aspecto é verificado pela variável $\mathrm{X}_{5}$

A variável $\mathrm{X}_{6}$ permite abordar aspectos ligados à saúde, às condições de trabalho no meio rural e a práticas que denotam efeitos no meioambiente, aprofundadas especialmente no processo de modernização da agricultura e que, de acordo com SESA/CSA (2005), coloca o Brasil entre os maiores consumidores de agrotóxicos do mundo.

A utilização de energia elétrica é comumente associada à questão do desenvolvimento. Estudo realizado por Martins (2002) relaciona o consumo de energia elétrica e o desenvolvimento socioeconômico dos municípios das regiões de Botucatu e Avaré. Podem-se citar também os trabalhos de Mata et al. (2004) sobre desenvolvimento econômico e social dos municípios do Estado da Bahia e o de Rezende e Parré (2004) a respeito do desenvolvimento da agricultura paranaense. As variáveis $\mathrm{X}_{7}$ e $\mathrm{X}_{8}$ espelham esta realidade.

Os indicadores de desempenho econômico $\left(\mathrm{X}_{9}\right.$ a $\left.\mathrm{X}_{16}\right)$ agregam variáveis relacionadas tradicionalmente ao desenvolvimento econômico. O número de pessoas ocupadas em atividades agrícolas $\left(\mathrm{X}_{9}\right)$ refere-se à população ocupada na agricultura, pecuária, silvicultura, exploração florestal e pesca. A produtividade do trabalho na agricultura $\left(\mathrm{X}_{10}\right)$ é medida pelo quociente entre o Valor Bruto da Produção Agropecuária (VBP) e o pessoal ocupado na agropecuária (população ocupada na agricultura, pecuária, silvicultura, exploração florestal e pesca). A renda municipal agrícola per capita $\left(\mathrm{X}_{11}\right)$ é medida pelo quociente entre o Valor Bruto da Produção Agropecuária (VBP) e a população total.

A produtividade dos fatores de produção está associada à estrutura e desempenho econômico de determinado setor. Neste sentido, as variáveis $\mathrm{X}_{13}$ e $\mathrm{X}_{14}$ denotam a produtividade da terra, expressa em tonelada/hectare das culturas de soja e milho. A escolha destas culturas foi determinada pela relevância das mesmas no processo de modernização 
agrícola do Paraná. As variáveis $\mathrm{X}_{15}$ e $\mathrm{X}_{16}$ incluem a questão do crédito no desenvolvimento rural. Estudo de Buainain e Souza Filho (2001) versando sobre o papel do crédito no desenvolvimento rural, afirma que a disponibilidade de recursos é um dos principais condicionantes da produção agropecuária.

As variáveis $\mathrm{X}_{17}$ e $\mathrm{X}_{18}$ pretendem verificar a contribuição da especialização na produção de determinada cultura para o fenômeno em estudo, partindo da idéia de que a maior especialização está comumente associada ao uso de agrotóxicos e, portanto, impactos no meio ambiente. Kageyama (2004) em trabalho sobre desenvolvimento rural dos municípios do Estado de São Paulo, utilizou para medir o índice de meio ambiente a ausência ou não de monocultura, considerando monocultura a utilização de $40 \%$ ou mais de área do estabelecimento ocupada com determinada cultura ou $50 \%$ ocupada com pastagens. Nesta pesquisa, por meio de dados relativos à área plantada total (com culturas temporárias e permanentes) e à área destinada à plantação de cada uma das culturas procurou-se inicialmente identificar as culturas que ocupassem $40 \%$ ou mais da área plantada total em cada município. Verificou-se que, para o ano em referência, as culturas de milho e soja foram as que apresentaram maior número de municípios com especialização em seu cultivo, além de estarem presentes em grande parte dos municípios paranaenses.

Os dados utilizados para a execução da pesquisa são secundários e têm como fontes: Fundação Instituto Brasileiro de Geografia e Estatística (IBGE), Instituto Paranaense de Desenvolvimento Econômico e Social (IPARDES), Departamento de Economia Rural da Secretaria de Agricultura e Abastecimento do Paraná (SEAB/DERAL), Banco Central do Brasil (BACEN), Centro de Saúde Ambiental da Secretaria de Saúde do Estado do Paraná (CSA/SESA), Instituto de Desenvolvimento Educacional do Paraná (FUNDEPAR) e Relação Anual de Informações Sociais do Ministério do Trabalho e Emprego (RAIS/MTE).

\section{Resultados}

A análise aplicada ao modelo para o ano de 2000 possibilitou a extração de cinco fatores com raiz característica maior que a unidade 
e que sintetizam as informações contidas nas 18 variáveis originais. Após rotação, conforme a Tabela 1, percebe-se que os cinco fatores selecionados explicam, em conjunto, $66,17 \%$ da variância total das variáveis selecionadas.

Tabela 1- Raiz característica, percentual explicado por cada fator e variância acumulada (\%)

\begin{tabular}{cccc}
\hline Fator & Raiz característica & $\begin{array}{c}\text { Variância explicada } \\
\text { pelo fator }(\%)\end{array}$ & $\begin{array}{c}\text { Variância acumulada } \\
(\%)\end{array}$ \\
\hline F1 & 3,981 & 22,117 & 22,117 \\
F2 & 2,678 & 14,877 & 36,994 \\
F3 & 1,929 & 10,716 & 47,710 \\
F4 & 1,855 & 10,306 & 58,016 \\
F5 & 1,467 & 8,151 & 66,167 \\
\hline
\end{tabular}

Fonte: Resultados da pesquisa

O teste de Bartlett $^{2}$ mostrou-se significativo, rejeitando a hipótese nula de que a matriz de correlação é uma matriz identidade. O teste de KMO, para análise da adequabilidade da amostra apresentou valor de 0,716, indicando que a amostra é passível de ser analisada pelas técnicas da análise fatorial.

A Tabela 2 apresenta as cargas fatoriais e as comunalidades para os fatores considerados. Para sua interpretação, foram consideradas apenas as cargas fatoriais com valores superiores a 0,50 (destacadas em negrito). Os valores encontrados para as comunalidades revelam que praticamente todas as variáveis têm sua variabilidade captada e representada pelos cinco fatores.

Percebe-se que o fator $\mathrm{F} 1$ está positiva e fortemente relacionado com os indicadores $\mathrm{X}_{5}$, que expressa o número de alunos matriculados; com os indicadores $\mathrm{X}_{7}$ e $\mathrm{X}_{8}$, que denotam a utilização de energia elétrica no meio rural; com a variável $\mathrm{X}_{9}$, que refere-se ao número de pessoas ocupadas em atividades agrícolas e com os indicadores $\mathrm{X}_{15}$ e $\mathrm{X}_{16}$, que expressam variáveis relacionadas à utilização de financiamentos. Observa-se aí que as variáveis determinantes estão ligadas a

\footnotetext{
${ }^{2}$ Teste BTS: 3.563,429 (nível de significância: 0,000).
} 
uma estrutura necessária para a produção: educação, mão-de-obra, energia e recursos financeiros.

Tabela 2 - Cargas fatoriais e comunalidades

\begin{tabular}{|c|c|c|c|c|c|c|}
\hline \multirow{2}{*}{ Indicadores } & \multicolumn{5}{|c|}{ Cargas Fatoriais } & \multirow{2}{*}{ Comunalidades } \\
\hline & $\mathrm{F} 1$ & $\mathrm{~F} 2$ & F3 & $\mathrm{F} 4$ & F5 & \\
\hline $\mathrm{X}_{1}$ & $-0,018$ & $-0,071$ & $-0,103$ & $-0,158$ & 0,743 & 0,594 \\
\hline $\mathrm{X}_{2}$ & $-0,091$ & 0,781 & 0,138 & 0,113 & $-0,284$ & 0,731 \\
\hline $\mathrm{X}_{3}$ & $-0,290$ & $-0,616$ & 0,109 & 0,089 & 0,082 & 0,490 \\
\hline $\mathrm{X}_{4}$ & 0,079 & $-0,723$ & 0,150 & 0,031 & 0,019 & 0,552 \\
\hline$X_{5}$ & 0,633 & 0,518 & $-0,200$ & $-0,002$ & 0,018 & 0,709 \\
\hline $\mathrm{X}_{6}$ & 0,355 & $-0,119$ & $-0,279$ & 0,151 & 0,490 & 0,481 \\
\hline $\mathrm{X}_{7}$ & 0,855 & $-0,164$ & 0,196 & 0,048 & 0,108 & 0,810 \\
\hline $\mathrm{X}_{8}$ & 0,911 & 0,205 & $-0,087$ & 0,054 & $-0,043$ & 0,884 \\
\hline $\mathrm{X}_{9}$ & 0,864 & 0,196 & $-0,268$ & 0,064 & 0,116 & 0,875 \\
\hline$X_{10}$ & 0,071 & $-0,185$ & 0,874 & 0,107 & 0,040 & 0,817 \\
\hline $\mathrm{X}_{11}$ & $-0,162$ & 0,120 & 0,799 & 0,224 & $-0,213$ & 0,774 \\
\hline $\mathrm{X}_{12}$ & 0,015 & 0,025 & 0,065 & 0,059 & 0,624 & 0,398 \\
\hline$X_{13}$ & 0,127 & $-0,041$ & 0,102 & 0,874 & $-0,039$ & 0,793 \\
\hline $\mathrm{X}_{14}$ & 0,209 & 0,282 & 0,373 & 0,529 & 0,135 & 0,560 \\
\hline$X_{15}$ & 0,571 & $-0,270$ & 0,194 & 0,117 & 0,258 & 0,517 \\
\hline $\mathrm{X}_{16}$ & 0,777 & 0,042 & 0,044 & 0,285 & $-0,096$ & 0,697 \\
\hline $\mathrm{X}_{17}$ & 0,084 & 0,638 & 0,149 & $-0,169$ & 0,159 & 0,491 \\
\hline $\mathrm{X}_{18}$ & 0,144 & $-0,397$ & 0,103 & 0,738 & $-0,039$ & 0,735 \\
\hline
\end{tabular}

Fonte: Resultados da pesquisa

De acordo com Costa, Costa e Eck (1999) um dos requisitos básicos para o desenvolvimento das regiões rurais associa-se à energia elétrica, que basicamente pode atender necessidades básicas (domésticas ou comunitárias, incluindo iluminação, lazer, educação, saúde, água potável e comunicação) e necessidades produtivas (derivadas de operações agro-industriais, incluindo o bombeamento de água para fins de irrigação, processamento de produtos, entre outras). Hoffmann (1992), em trabalho sobre a dinâmica da modernização da agricultura em microrregiões homogêneas do Brasil, identificou, 
no fator que reflete a intensidade de exploração da terra, a contribuição das variáveis energia elétrica e financiamentos. Ademais, como afirmam Buainain e Souza Filho (2001), a agricultura tem especificidades que requerem instrumentos de crédito apropriados, ou seja, a maior variabilidade da renda agrícola aumenta a dependência dos produtores em relação ao crédito, já que a alternância de anos bons e anos ruins reduz a capacidade de autofinanciamento dos produtores. Sendo assim, a disponibilidade de recursos financeiros é condição necessária, embora não suficiente, para permitir que os produtores iniciem e mantenham um processo produtivo rentável e sustentável.

O fator F2 é positiva e fortemente relacionado com os indicadores $\mathrm{X}_{2}$ (proporção de população rural), $\mathrm{X}_{5}$ (número de alunos matriculados nos ensinos pré-escolar, fundamental e médio na zona rural) e $\mathrm{X}_{17}$ (área plantada com milho/área plantada total), e é negativamente relacionado aos indicadores $\mathrm{X}_{3}$ (migrantes - proporção de pessoas naturais de outros municípios) e $\mathrm{X}_{4}$ (proporção de domicílios rurais com instalação sanitária). Verifica-se, portanto, que F2 está associado ao contingente de pessoas que vivem no meio rural e às suas atividades ligadas a estudos, cultivo, mobilidade e condições de habitação.

No fator $\mathrm{F} 3$ predominam as variáveis $\mathrm{X}_{10}$ (produtividade do trabalho na agricultura) e $\mathrm{X}_{11}$ (renda municipal agrícola per capita). Portanto, o fator F3 está relacionado à estrutura e desempenho econômico do setor. Estes indicadores de desempenho econômico agregam variáveis relacionadas tradicionalmente ao desenvolvimento econômico: produtividade e renda.

O fator F4, por sua vez, está positiva e fortemente relacionado com os indicadores $\mathrm{X}_{13}$ (produtividade da terra - soja), $\mathrm{X}_{14}$ (produtividade da terra - milho) e $\mathrm{X}_{18}$ (área plantada com soja/área plantada total). Assim, as variáveis determinantes deste fator também se relacionam à estrutura e desempenho do setor, perseguidos como meta de desenvolvimento da agricultura: a produtividade. Não obstante, a monocultura (especialização) constituiu-se um ponto central do processo de modernização da agricultura.

$\mathrm{O}$ último fator considerado, F5, está positiva e fortemente relacionado com os indicadores $\mathrm{X}_{1}$ (densidade demográfica) e $\mathrm{X}_{12}$ (salário 
nominal na agropecuária). Desse modo, contribuíram para este fator indicadores de população e renda. Indicadores de população de modo geral, deveriam favorecer o desenvolvimento rural, uma vez que, em tese, quanto maior a densidade demográfica, menor o isolamento das áreas rurais e maiores as oportunidades de estabelecimento de redes sociais. Já indicadores de renda são sempre relacionados à questão do desenvolvimento.

Uma vez verificadas as cargas fatoriais, o passo seguinte é observar os escores fatoriais, ou seja, o valor do fator para cada município do estado. A análise do fator deve ser feita levando em conta que seus escores originais, quando considerados todos os municípios em conjunto, são variáveis com média zero e desvio padrão igual a 1. Portanto, pode-se interpretar que os escores com valores próximos de zero indicam nível de desenvolvimento médio e, quanto maior em relação a zero for o fator, mais avançado será o município, no que se refere ao significado do fator em consideração. A Tabela 4 - Anexo, apresenta os resultados por município.

O IDR médio situou-se em 43,63. A partir daí, foram definidas as categorias de desenvolvimento rural. A Tabela 3 mostra que, de acordo com a classificação, seis municípios apresentaram grau de desenvolvimento muitíssimo alto. Na segunda categoria, muito alto, outros sete municípios se destacam. Já com grau de desenvolvimento alto, foram observados 50 municípios. Estes 63 municípios representam 15,79\% do total dos municípios paranaenses. Classificados com grau de desenvolvimento médio encontram-se 116 municípios, ou seja, 29,07\% do total. É, então, importante destacar que a maioria dos municípios, 220 ou $55,14 \%$, encontra-se nas categorias de baixo, muito baixo e muitíssimo baixo desenvolvimento.

Verifica-se que com grau de desenvolvimento mais elevado (MMA) não se constata a presença de municípios das mesorregiões Noroeste, Centro Ocidental, Norte Pioneiro, Sudoeste, Centro-Sul e Metropolitana de Curitiba (RMC). Na classificação muito alto (MA) não se registram municípios das mesorregiões Noroeste, Norte Central, Norte Pioneiro, Oeste e Centro Sul. Na classificação alto (A) não aparecem municípios das mesorregiões Noroeste, Centro Ocidental e Norte Pioneiro. Nas classificações médio (M) e baixo (B) observa-se a presença de muni- 
cípios de todas as mesorregiões. Na classificação muito baixo (MB) encontram-se municípios de metade das mesorregiões. Na classificação muitíssimo baixo (MMB) aparecem municípios apenas da mesorregião Metropolitana de Curitiba.

Tabela 3 - Grau de desenvolvimento rural dos municípios paranaenses, por mesorregião

\begin{tabular}{lcccc|c|c|c|c}
\hline \multirow{2}{*}{ Mesorregião } & \multicolumn{6}{|c}{ Número de municípios por grau de desenvolvimento } \\
\cline { 2 - 8 } & MMA & MA & A & M & B & MB & MMB \\
\hline Noroeste & 00 & 00 & 00 & 03 & 32 & 26 & 00 \\
Centro Ocidental & 00 & 01 & 00 & 07 & 17 & 00 & 00 \\
Norte Central & 01 & 00 & 01 & 14 & 53 & 10 & 00 \\
Norte Pioneiro & 00 & 00 & 00 & 04 & 28 & 14 & 00 \\
Centro Oriental & 02 & 02 & 05 & 01 & 04 & 00 & 00 \\
Oeste & 02 & 00 & 07 & 24 & 16 & 01 & 00 \\
Sudoeste & 00 & 02 & 09 & 25 & 01 & 00 & 00 \\
Centro Sul & 00 & 00 & 12 & 16 & 01 & 00 & 00 \\
Sudeste & 01 & 01 & 11 & 07 & 01 & 00 & 00 \\
RMC & 00 & 01 & 05 & 15 & 11 & 03 & 02 \\
\hline Total & 06 & 07 & 50 & 116 & 164 & 54 & 02 \\
\hline
\end{tabular}

Fonte: Resultados da pesquisa

De acordo com o IPARDES (2004), entre as mesorregiões que integram a expansão da fronteira agrícola do estado, baseadas no avanço da cafeicultura, a Noroeste foi a que apresentou maior dificuldade para transitar da crise cafeeira (dos anos 1960/70) para o novo padrão da atividade agrícola. Tal dificuldade pode estar relacionada às limitações do uso do solo, determinada pela ocorrência do arenito Caiuá, o que inviabilizou a expansão mais acentuada de culturas anuais, fazendo com que a pecuária extensiva fosse a opção ao declínio do café. Desse modo, mesmo com avanços nas técnicas de manejo e conservação dos solos e a expansão de algumas culturas agrícolas, as atividades agropecuárias mantêm participação expressiva na ocupação da mão-de-obra regional e apresentam, comparativamente a outras mesorregiões, indicadores de produtividade mais baixos e estão es- 
truturadas principalmente em torno da pecuária. Segundo a mesma fonte, relativamente a indicadores sociais, a mesorregião, que tem como centros os municípios de Paranavaí, Umuarama e Cianorte, fica aquém do padrão médio estadual, encontrando 13 municípios entre os 100 menores IDH-M do estado (IPARDES, 2003). Sob o foco rural, a mesorregião não apresentou municípios nas categorias MMA, MA e A concentrando grande parte nas categorias $\mathrm{B}$ e $\mathrm{MB}$, o que reflete a grave situação da população rural.

A mesorregião Centro Ocidental, que tem como principal centro Campo Mourão, possui duas áreas fisiográficas, a maior delas com presença do arenito Caiuá. Sua ocupação é fruto de dois fluxos, um deles oriundo do norte do estado, relacionado à expansão do café, e outro decorrente de movimentos de gaúchos e catarinenses, com a policultura alimentar. A economia regional baseia-se na agricultura e agroindústria, que se consolidaram com o processo de modernização ocorrido a partir dos anos 70, porém sem elevar a participação na renda gerada no estado. Nos anos 90, consolidou-se como produtora de grãos, contudo, sofreu grande impacto com o revés ocorrido na cultura do algodão, com grande importância pela demanda de trabalho agrícola (IPARDES, 2004). É de se destacar que em 2000, nenhum de seus municípios apresentou valores do IDH-M acima do verificado para o estado (IPARDES, 2003). Pelos resultados desta pesquisa, mais da metade dos municípios apresentaram índice de desenvolvimento rural abaixo da média. Contudo, é de se destacar que um (Campo Mourão) obteve classificação MA, o que reflete o problema vivenciado também no aspecto rural.

A mesorregião Norte Central, que tem como principais centros os municípios de Londrina, Maringá e Apucarana, destaca-se pelo pioneirismo em termos de ocupação, tendo como base desse processo a cultura do café assentada na pequena propriedade vinculada ao mercado. Arraigada na modernização da agropecuária e no aprofundamento da agroindustrialização, sua base agropecuária se manteve competitiva, reforçando sua articulação com a agroindústria e o mercado. Destaque se dá às culturas de soja e milho, sem deixar de mencionar o avanço principalmente da fruticultura. Outra característica importante da base produtiva é a sua organização em cooperativas (IPARDES, 2004). Os 
indicadores relativos à dimensão social apontam para a forte heterogeneidade entre os municípios. De modo geral, o conjunto de municípios que compõem o eixo Londrina-Maringá apresenta as situações mais favoráveis em termos do IDH-M, com algumas exceções em municípios periféricos aos pólos (IPARDES, 2003). Destacando-se o verificado neste trabalho, ressalta-se que apenas um município (Londrina) encontra-se na classificação MMA, sendo que a grande maioria encontra-se nos graus médio e inferiores, o que denota disparidade entre os municípios e entre o rural e o urbano da mesorregião.

A mesorregião Norte Pioneiro, que tem como principais centros Cornélio Procópio, Jacarezinho e Santo Antonio da Platina, foi ocupada, segundo o IPARDES (2004), a partir de meados do século XIX, como resultado da política imperial que visava integrar a província de Mato Grosso ao litoral brasileiro, e da frente pioneira. A crise da cultura cafeeira teve profundo impacto sobre a dinâmica demográfica da região. A transição do café para novas culturas e formas de produção voltou-se à produção de soja, trigo e cana, incorporando tecnologia, tendo por conseqüência o êxodo rural. Dados do IDH-M revelam que apenas Cornélio Procópio e Barra do Jacaré posicionam-se acima da média estadual, sendo que na área educacional (a que mais contribuiu para a melhoria do IDH-M na última década), a maioria dos municípios apresenta taxas de freqüência escolar e de alfabetização abaixo da média do Paraná. Os resultados desta pesquisa mostram que na mesorregião o problema também é visto sob o foco rural: dos 46 municípios, quatro $(8,69 \%)$ tiveram grau de desenvolvimento médio, situando-se, portanto, com valor acima da média do estado; 28 (60,87\%) apresentaram grau baixo e $14(30,44 \%)$ foram classificados com grau de desenvolvimento muito baixo, de modo que $91,31 \%$ dos municípios desta região tiveram resultados abaixo da média.

Segundo o IPARDES (2004) a mesorregião Centro Oriental organizou sua economia fundamentalmente a partir de grandes fazendas e sustentaram os ciclos econômicos do tropeirismo, da erva-mate e da madeira, complementados por um setor de subsistência, em pequenas áreas. Na década de 1970, o processo de modernização da agricultura possibilitou aos produtores da região alavancar uma produção intensiva em capital. A pauta agrícola regional incorporou 
a produção da soja combinada com o trigo e milho. Dados sobre IDHM mostram que, à exceção de Ponta Grossa, os demais municípios apresentam este indicador inferior ao do estado (IPARDES, 2003). Os resultados desta pesquisa mostraram que nesta mesorregião, não houve registro de municípios na categoria $\mathrm{MB}$ e $\mathrm{MMB}$, havendo, contudo, nas MMA, MA, A, M e B.

A dinâmica da mesorregião Oeste está associada à operação de um complexo agroindustrial moderno e competitivo, articulado aos eixos dinâmicos do país e do exterior. Os principais centros são Cascavel e Foz do Iguaçu. De acordo com o IPARDES (2003), do ponto de vista social, a mesorregião concentra 11 dos 23 municípios nas melhores posições do estado em termos de IDH-M, estando, contudo nesta mesma mesorregião muitos municípios com tais índices entre os piores do estado. Nesta pesquisa destacam-se com grau de desenvolvimento rural muitíssimo alto os municípios de Toledo e Cascavel. Registre-se que $66 \%$ dos municípios encontram-se com índice de desenvolvimento acima do valor do IDR médio. Contudo, há que se destacar que há registro de municípios nas categorias baixo e muito baixo, o que reflete uma disparidade observada entre os municípios de uma região absorvedora dos efeitos do processo de modernização da agricultura.

A mesorregião Sudoeste, que tem como centros os municípios de Francisco Beltrão e Pato Branco, é, segundo o IPARDES (2004), a segunda região menos urbanizada do estado, caracterizando-se como importante reduto da agricultura familiar, mesmo tendo passado por transformações na sua base produtiva, com a introdução de novas práticas de cultivo a partir da expansão da soja. Em relação ao desempenho social, a maioria dos municípios da mesorregião encontram-se em posições intermediárias no ranking do IDH-M. O desempenho é reflexo, principalmente, do componente educação (IPARDES, 2003). Pelos resultados deste trabalho, destaca-se o município de Francisco Beltrão e Dois Vizinhos com grau de desenvolvimento rural muito alto, além de outros nove com grau alto. Dos 37 municípios, 36 apresentaram IDR acima do valor médio. Um aspecto interessante é que a maioria dos municípios apresentou valores positivos do fator F2 (que tem alta correlação positiva com a proporção de população rural). Ora, sendo esta mesorregião uma das menos urbanizadas do estado, 
é importante atentar para o peso que tem o contingente de pessoas que vivem no meio rural. Chama-se atenção ainda para o fato de que o fator F2 apresentou correlação negativa com aspecto ligado a condições de vida (moradia) dessa população. Assim, torna-se evidente que, perseguir metas para melhorar as condições de habitação dessas pessoas é fundamental para se ter desenvolvimento.

Composta por 29 municípios, entre os quais se destacam Guarapuava e Palmas, e mesorregião Centro Sul é uma das menos urbanizadas, contribuindo com um dos maiores volumes na composição da população rural do estado, característica que, de acordo com o IPARDES (2004), é reforçada pelo elevado número de assentamentos rurais (34\% das famílias assentadas no Paraná) e áreas indígenas (62\%). Todos os municípios registram IDH-M abaixo da média paranaense, desempenho que se repete quanto aos componentes do índice (IPARDES, 2003). No que se refere aos resultados desta pesquisa, observa-se que não há registro de municípios nas categorias MMA e MA. Destacam-se 12 municípios classificados com grau A. Dezesseis municípios desta mesorregião apresentaram grau de desenvolvimento médio e um (Foz do Jordão) teve grau baixo. Também nesta região o fator F2 foi positivo para a maioria dos municípios. Cabe, então, aqui atentar para o fato (já apontado para a mesorregião Sudoeste) da importância da população rural e das condições em que esta vive, isto se evidenciando e sendo possível ficar mais claro em mesorregiões e municípios onde a população rural é expressiva.

A mesorregião Sudeste é, segundo o IPARDES (2004), uma das áreas de ocupação mais antigas do Paraná. A evolução da agropecuária denota intensificação da produção via aumento de produtividade dos principais produtos regionais, contribuindo para alteração na pauta dos produtos, ascendendo culturas como soja, milho, erva-mate e fumo, sem que as demais (batata e feijão) apresentarem redução. À exceção de União da Vitória, todos os municípios apresentam IDH-M inferior ao índice médio do Paraná (IPARDES, 2003). Contudo, em relação ao setor rural enfocado nesta pesquisa, os resultados mostraram que a maioria dos municípios apresentaram índice acima do valor médio, havendo presença de municípios em todas as categorias, o que denota heterogeneidade no meio rural entre os municípios desta região.

Torna-se importante destacar que o fator F2 se sobressai em municí- 
pios com maior proporção de pessoas na zona rural, trazendo resultados importantes para a classificação de seus graus de desenvolvimento rural, de maneira geral, acima do médio, o que pode parecer paradoxal, porque também mostra correlação alta e negativa com aspecto de bem-estar da população rural. Neste ponto, é fundamental perceber a necessidade de melhorar as condições de vida da população rural, uma vez que é o volume (proporção de população rural) que está influenciando de forma significativa a classificação de municípios com tal característica quanto ao seu grau de desenvolvimento rural. Isto se reforça ao se juntar aos outros fatores com resultados negativos, que estão ligados à energia elétrica, crédito rural e renda.

A mesorregião Metropolitana de Curitiba (RMC) é particularizada, segundo o IPARDES (2004), pelo processo de concentração de população e atividades que se intensificou a partir da década de 1970. Parte substantiva dos fluxos populacionais, decorrentes da evasão ocorrida no meio rural do estado convergiu para Curitiba e adjacências, em grande medida sob estímulos de políticas de desenvolvimento regional e urbano. Em contraposição às áreas de concentração e marcando a heterogeneidade da mesorregião, existem municípios que se caracterizam pela presença maior de população rural, baixo crescimento populacional, precariedade de serviços sociais e incipiente atividade econômica. Em contraposição aos municípios com condição socioeconômica favorável, alguns municípios de pequeno porte, com fortes restrições ao desenvolvimento agrícola, mas com importante participação da população rural e distantes do pólo metropolitano, apresentam as situações mais precárias nas dimensões sociais, apresentando valores do IDH-M entre os mais baixos do estado. Esta heterogeneidade também é constatada pelos resultados obtidos nesta pesquisa, onde se verificou que um município (Lapa) teve classificação MA e outros cinco tiveram classificação A. Observou-se, ademais, que quase metade dos municípios (16 dos 37) tiveram índice abaixo da média.

Estes resultados deixam transparecer que as desigualdades regionais no Paraná manifestam-se também em relação às condições da população rural. A análise, no que se refere aos municípios, mostra que estas desigualdades se repetem e, por vezes, se intensificam no interior das mesorregiões. 


\section{Conclusões}

O Brasil vive, há décadas, diante de uma questão polêmica e pouco resolvida para a sociedade: a questão agrária. A noção de desenvolvimento aplicada a um corte territorial (rural-urbano) pode ser controversa, mas pode-se dizer que há um consenso a respeito da idéia de que o desenvolvimento rural não deve ser exclusivamente econômico, pautado apenas no desempenho agropecuário, mas precisa incluir também aspectos sociais e ambientais. Diante disso, discute-se o nível de desenvolvimento alcançado pelo rural, inserido em um modelo que previa que o desenvolvimento agrícola teria como conseqüência o desenvolvimento rural.

O setor agrícola do Paraná passou por uma reorganização produtiva, apontando para um processo de melhoria da competitividade e para a consolidação de uma estrutura de produção adaptada ao ambiente econômico de maior concorrência, com resultados expressivos para a agropecuária, colocando o estado em destaque. Contudo, toda essa mudança gerou impactos sobre aspectos fundiários, demográficos, de ocupação da força de trabalho. Essas alterações colocam em questão a visão do desenvolvimento rural associada apenas à idéia de desenvolvimento agrícola. Isso se deve ao fato de que as proposições do modelo adotado, apesar de terem elevado enormemente a produção agrícola, não resolveram o problema da pobreza rural e nem criaram um padrão de vida rural que atendesse às necessidades dos que vivem no campo.

Os resultados dos fatores apontam para aspectos que devem ser trabalhados de forma mais intensa, no sentido de melhorar a vida no campo e, por conseguinte a situação dos municípios, alertando para as especificidades que devem ser consideradas.

Considerando o aspecto fundamental de que rural não é apenas sinônimo de agrícola, o grande número de municípios em situação de baixo nível de desenvolvimento rural permite visualizar a heterogeneidade de situações, num estado que teve o processo de modernização de sua agricultura difundido, e exige atenção para o meio rural: os resultados expressivos da agropecuária paranaense, que coloca o estado em evidência, não se refletem em todo o espaço rural. 


\section{Referências bibliográficas}

BONI, C.E. e CUNHA, M.S. Evolução da estrutura fundiária no estado do Paraná no período de 1970 a 1995/96. In: Agronegócio paranaense - potencialidades e desafios. Cascavel. Edunioeste, 2002. p. 145-162.

BUAINAIN, A M. e SOUZA FILHO, H.M. Elementos para análise e desenho de políticas de crédito para agricultura familiar. NEA,IE/UNICAMP. São Carlos, 2001.

COSTA, H.S; COSTA, R.A L.; ECK, M. Análise econômica comparativa da eletrificação rural comercial e fotovoltaica. Universidade Federal de Pernambuco, Recife, 1999.

CUNHA, N.R.S; LIMA, J.E.; MOURA, L.R.C. Degradação ambiental nos estados de Goiás e Tocantins. Congresso da SOBER. SOBER. Ribeirão Preto, 2005.

FERREIRA JÚNIOR, S.; BAPTISTA,A J.M.S. e LIMA, J.E. A modernização agropecuária nas microrregiões do Estado de Minas Gerais. Congresso da SOBER. SOBER. Juiz de Fora, 2003.

HADDAD, P.R. et al. Economia regional. Fortaleza, BNB, 1989.

HOFFMANN, R. A dinâmica da modernização da agricultura em 157 microrregiões homogêneas do Brasil. Revista de Economia e Sociologia Rural. Brasília, v. 30, n.4, p.271-290, out/dez. 1992.

INSTITUTO PARANANENSE DE DESENVOLVIMENTO ECONÔMICO E SOCIAL -IPARDES. Leituras Regionais: Mesorregiões geográficas do Paraná. Curitiba, 2004.

IPARDES. Índice de Desenvolvimento Humano Municipal 2000: anotações sobre o desempenho do Paraná. Curitiba, 2003.

KAGEYAMA, A A . Desenvolvimento rural: conceito e um exemplo de medida. Congresso da SOBER. SOBER. Cuiabá, 2004.

LLANILLO,R.F.; PELLINI, T. e DORETTO,M. Territórios rurais no Paraná. Congresso da SOBER. SOBER. Cuiabá, 2004.

MARTINS, C.M. Consumo de energia elétrica e desenvolvimento sócio-econômico nas regiões de Botucatu e Avaré. Universidade Estadual 
Paulista “Júlio de Mesquita Filho”. Faculdade de Ciências Agronômicas. Campus de Botucatu. Dissertação de Mestrado. Botucatu, 2002.

MATA, H.T.C et al. Padrão e determinantes do desenvolvimento econômico e social dos municípios do Estado da Bahia: a dicotomia rural-urbano. Congresso da SOBER. SOBER. Cuiabá, 2004.

MATTEI,L. A pluriatividade no contexto do desenvolvimento rural catarinense. IE/UNICAMP. Disponível em: http://www.eco.unicamp. $\mathrm{br} /$ nea/rurbano/textos

MELO,C.O. Caracterização do desenvolvimento rural dos municípios paranaenses: uma análise com base na estatística multivariada. Universidade Estadual de Maringá. Departamento de Economia. Dissertação de Mestrado. Maringá, 2006.

MELO, C.O.; PARRÉ, J.L. Caracterização do desenvolvimento rural dos municípios paranaenses. Congresso da SOBER. SOBER. Fortaleza, 2006.

MONTEIRO, V.P.; PINHEIRO, J.C. Critério para implantação de tecnologias de suprimentos de água potável em municípios cearenses afetados pelo alto teor de sal. Revista de Economia e Sociologia Rural. Rio de Janeiro, vol. 42, n. 02, p. 365-387, abr/jun 2004.

PEREIRA, L.B. O Estado e as transformações recentes da agricultura paranaense. Universidade Federal de Pernambuco. Centro de Ciências Sociais Aplicadas. Departamento de Economia. Tese de Doutorado. Recife, 1987.

REZENDE, L.P. e PARRÉ, J.L. Comparação do grau de desenvolvimento agrícola dos municípios paranaenses. Congresso da SOBER.. SOBER. Juiz de Fora, 2003.

REZENDE, L.P. e PARRÉ, J.L. A regionalização da agricultura paranaense na década de 1990: um estudo utilizando estatística multivariada. Congresso da SOBER. SOBER. Cuiabá, 2004.

ROSADO, P.L; ROSSATO, M.V. e LIMA, J.E. Hierarquização e desenvolvimento sócio-econômico das microrregiões de Minas Gerais: uma análise regional. Congresso da SOBER. SOBER. Ribeirão Preto, 2005.

SESA/CSA-SECRETARIA DE ESTADO DA SAÚDE/CENTRO DE SAÚDE AMBIENTAL -Aspectos epidemiológicos, toxicológicos e clínicos das 
intoxicações por agrotóxicos. Disponível em http://www.saude.pr.gov. br/saudeambiental. Acesso: 30.maio.2005.

SILVA,G.H.; MELO,C.O.; ESPERANCINI,M.S.T. Regionalização do desenvolvimento econômico e social dos municípios da região oeste paranaense. IV Encontro Nacional da Associação Brasileira de Estudos Regionais. IV ABER. Foz do Iguaçu, 2006.

SILVA, R.G. e FERNANDES, E.A Índice relativo de modernização agrícola da região Norte. Congresso da SOBER. SOBER. Cuiabá, 2004.

SOUZA, M. Atividades não-agrícolas e desenvolvimento rural no estado do Paraná. Universidade Estadual de Campinas. Faculdade de Engenharia Agrícola. Tese de Doutorado. Campinas, 2000.

VEIGA, J.E. A face rural do desenvolvimento - natureza, território e agricultura. Porto Alegre, Editora Universidade, UFRS. 2000.

ZAMBRANO,C.E. e PINTO, W.J. Avaliação do desenvolvimento municipal do Estado de Mato Grosso aplicando análise multivariada. Congresso da SOBER. SOBER. Cuiabá, 2004. 


\section{Anexo}

Tabela 4 - Fatores, índice bruto (IB), índice de desenvolvimento rural (IDR) e grau de desenvolvimento (GD), dos municípios paranaenses, por ordem de classificação no Estado

\begin{tabular}{|c|c|c|c|c|c|c|c|c|c|c|}
\hline Município & Mesorregião & $F 1$ & $F 2$ & F3 & F4 & F5 & $I B$ & $I D R$ & $G D$ & $\begin{array}{l}\text { Classi- } \\
\text { fic. }\end{array}$ \\
\hline Castro & C.Oriental & 4,44751 & 0,06814 & 2,50592 & $-0,0101$ & 0,60386 & 1,98060 & 100,00 & MMA & 1 \\
\hline Toledo & Oeste & 5,40348 & $-2,1182$ & 3,17137 & $-0,72433$ & $-0,11391$ & 1,71667 & 92,49 & MMA & 2 \\
\hline Prudentópolis & Sudeste & 5,07229 & 2,25118 & $-2,28103$ & $-0,21262$ & $-1,21988$ & 1,64880 & 90,56 & MMA & 3 \\
\hline Cascavel & Oeste & 5,14359 & $-2,0140$ & 0,49614 & 0,34932 & 1,88721 & 1,63370 & 90,13 & MMA & 4 \\
\hline Londrina & N.Central & 3,68756 & $-1,1260$ & $-2,31359$ & 1,09956 & 5,5634 & 1,46133 & 85,22 & MMA & 5 \\
\hline Carambeí & C.Oriental & 0,94621 & $-0,1689$ & 5,47498 & 0,2871 & 1,82247 & 1,43421 & 84,45 & MMA & 6 \\
\hline Lapa & RMC & 3,19574 & 1,47393 & $-0,61023$ & $-0,23077$ & $-0,04219$ & 1,25963 & 79,48 & MA & 7 \\
\hline Palmeira & C.Oriental & 2,48317 & 0,98906 & $-0,26204$ & 1,37818 & 0,18852 & 1,24785 & 79,14 & MA & 8 \\
\hline Francisco Beltrão & Sudoeste & 3,70081 & 0,26423 & 0,38786 & $-0,9123$ & $-0,34692$ & 1,17442 & 77,05 & MA & 9 \\
\hline S.Matueus do Sul & Sudeste & 2,64105 & 1,17319 & $-0,55849$ & 0,55961 & $-0,42946$ & 1,09038 & 74,66 & MA & 10 \\
\hline Dois Vizinhos & Sudoeste & 2,98336 & 0,21088 & 1,00487 & $-0,43159$ & $-0,48156$ & 1,08083 & 74,39 & MA & 11 \\
\hline Campo Mourão & C.Ocidental & 3,13125 & $-2,61578$ & 1,0387 & 0,27747 & 2,48242 & 0,97576 & 71,40 & MA & 12 \\
\hline Tibagi & C.Oriental & 0,60177 & 0,79439 & 1,85968 & 1,43615 & 0,54251 & 0,97146 & 71,28 & MA & 13 \\
\hline Guarapua & C.Sul & 2,89977 & $-0,60945$ & 0,07218 & 0,32711 & 0,34954 & 0,93794 & 70,32 & A & 14 \\
\hline Palotina & Oeste & 2,45969 & $-1,52178$ & 3,77673 & $-1,23148$ & 0,29352 & 0,93602 & 70,27 & A & 15 \\
\hline Mangueirinha & C.Sul & & 0,91373 & 0,47467 & 1,36595 & $-0,33391$ & 0,92033 & 69,82 & A & 16 \\
\hline Pitanga & C.Sul & 2,66511 & 1,00000 & $-1,23117$ & 0,44545 & $-0,73216$ & 0,89547 & 69,11 & A & 17 \\
\hline Ipiranga & Sudeste & 1,41887 & 1,60247 & $-0,42706$ & 1,24078 & $-0,54914$ & 0,89102 & 68,99 & A & 18 \\
\hline Arapoti & C.Oriental & 1,26622 & $-0,26162$ & 2,67385 & 0,01582 & 0,48753 & 0,85998 & 68,10 & A & 19 \\
\hline Chopinzinho & Sudoeste & 2,00236 & 0,66132 & $-0,38824$ & 1,46999 & $-1,03381$ & 0,85673 & 68,01 & A & 20 \\
\hline Pinhão & C.Sul & 1,00169 & 1,82267 & $-0,84014$ & 1,18999 & 0,48770 & 0,85399 & 67,93 & A & 21 \\
\hline Cantagalo & C.Sul & $-0,57768$ & 1,66625 & $-0,14797$ & 1,09623 & 4,17062 & 0,84209 & 67,59 & A & 22 \\
\hline Mal.Cand.Rondon & Oeste & 3,54373 & $-1,23150$ & 0,91960 & $-0,88904$ & $-0,88120$ & 0,80954 & 66,67 & A & 23 \\
\hline Irati & Sudeste & 2,02172 & 0,67559 & $-2,10230$ & 0,73179 & 1,50171 & 0,78618 & 66,00 & A & 24 \\
\hline Curitiba & RMC & $-0,87230$ & 0,38734 & $-0,72102$ & $-2,06230$ & 11,53790 & 0,77885 & 65,79 & A & 25 \\
\hline Capanema & Sudoeste & 2,13560 & 0,06538 & $-0,55771$ & 1,07972 & $-0,23505$ & 0,77744 & 65,75 & A & 26 \\
\hline Pato Branco & Sudoeste & 1,73338 & $-0,67604$ & $-0,11401$ & 1,27409 & 1,11016 & 0,74414 & 64,81 & A & 27 \\
\hline Ponta Grossa & C.Oriental & 1,67077 & $-0,57277$ & $-0,30797$ & 1,18938 & 1,35404 & 0,73187 & 64,46 & A & 28 \\
\hline Cafelândia & Oeste & 0,47276 & $-0,98168$ & 4,15945 & 0,22370 & 0,48121 & 0,70506 & 63,69 & A & 29 \\
\hline $\begin{array}{l}\text { Cel. } \\
\text { Domingos Soares }\end{array}$ & C.Sul & $-0,57400$ & 2,22714 & $-0,19921$ & 1,90987 & 1,03506 & 0,70160 & 63,60 & A & 30 \\
\hline Nova Laranjeiras & C.Sul & 0,36911 & 2,60840 & $-0,26816$ & $-0,0890$ & 0,25105 & 0,68348 & 63,08 & A & 31 \\
\hline Guaraniaçu & Oeste & 0,74398 & 1,11731 & 0,44522 & 0,79494 & $-0,14376$ & 0,67811 & 62,93 & A & 32 \\
\hline $\begin{array}{l}\text { S.Miguel do } \\
\text { Iguaçu }\end{array}$ & Oeste & 1,89705 & $-0,60546$ & 0,92882 & 0,66179 & $-0,60129$ & 0,67741 & 62,91 & A & 33 \\
\hline Ortigueira & C.Oriental & 1,18986 & 2,16626 & $-1,32495$ & 0,22201 & $-0,34147$ & 0,66271 & 62,49 & A & 34 \\
\hline
\end{tabular}




\begin{tabular}{|c|c|c|c|c|c|c|c|c|c|}
\hline Teixeira Soares & Sudeste & 0,23980 & 0,84496 & 1,63853 & 0,73663 & 0,05782 & 0,65736 & 62,34 & A \\
\hline Catanduvas & Oeste & 0,05401 & 1,08503 & 1,17588 & 1,08382 & 0,28246 & 0,65605 & 62,30 & A \\
\hline Antonio Olinto & Sudeste & $-0,32801$ & 1,98095 & 0,63448 & 0,97331 & 0,52567 & 0,65487 & 62,27 & A \\
\hline Imbituva & Sudeste & 1,72907 & 0,44731 & $-0,63882$ & 1,06748 & $-0,73074$ & 0,65132 & 62,16 & A \\
\hline João do Triunfo & Sudeste & 0,98675 & 1,99522 & $-1,12583$ & 0,82001 & $-0,60112$ & 0,64977 & 62,12 & A \\
\hline S.José dos Pinhais & $\mathrm{RMC}$ & 1,91697 & 0,33312 & $-0,80651$ & $-0,83731$ & 1,48408 & 0,63745 & 61,77 & A \\
\hline Marmeleiro & Sudoeste & 0,61550 & 0,74138 & 0,78573 & 0,36406 & 0,59180 & 0,62928 & 61,54 & A \\
\hline Rio Bonito Iguaçu & C.Sul & 0,41823 & 2,04783 & $-0,74005$ & 0,51483 & 0,45489 & 0,61660 & 61,18 & A \\
\hline Cândido de Abreu & N.Central & 1,05986 & 2,21163 & $-1,20616$ & 0,03030 & $-0,39476$ & 0,61228 & 61,05 & A \\
\hline Candói & C.Sul & 0,04994 & 1,10466 & 0,69456 & 1,20187 & 0,29702 & 0,60134 & 60,74 & A \\
\hline Cruz Machado & Sudeste & 1,84325 & 1,77343 & $-0,09788$ & $-1,67019$ & $-1,26289$ & 0,58329 & 60,23 & A \\
\hline Rio Azul & Sudeste & 1,26972 & 1,63908 & $-0,83412$ & 0,17507 & $-0,86091$ & 0,57907 & 60,11 & A \\
\hline Doutor Ulysses & RMC & $-0,53251$ & 2,98022 & 1,03121 & $-1,2526$ & 0,69948 & 0,55015 & 59,28 & A \\
\hline $\begin{array}{l}\text { Bom Sucesso } \\
\text { do Sul }\end{array}$ & Sudoeste & $-0,72522$ & 0,70610 & 1,96401 & 1,77124 & 0,30170 & 4747 & 59,21 & A \\
\hline Renascença & Sudoeste & $-0,39553$ & 0,46883 & 2,21692 & 1,15408 & 0,25378 & 0,54326 & 59,09 & A \\
\hline Quitandinha & RMC & 1,31801 & 2,19597 & $-0,50312$ & $-1,69599$ & $-0,39464$ & 0,54004 & 59,00 & A \\
\hline Verê & Sudoeste & 0,51621 & 0,84218 & 0,90668 & 0,51660 & $-0,47739$ & 0,53040 & 58,72 & A \\
\hline Piraí do Sul & C.Oriental & 0,45330 & 0,81185 & 0,50570 & 0,59191 & 0,15899 & 0,52773 & 58,65 & A \\
\hline Coronel Vivida & Sudoeste & 1,45677 & 0,07080 & $-0,64099$ & 1,18318 & $-0,46149$ & 0,52648 & 58,61 & A \\
\hline Goioxim & C.Sul & $-0,08921$ & 2,06524 & $-0,37600$ & 0,67348 & 0,38030 & 0,52538 & 58,58 & A \\
\hline Honório Serpa & C.Sul & $-0,48815$ & 1,29694 & 0,54945 & 1,70744 & 0,23746 & 0,51261 & 58,22 & A \\
\hline Guamiranga & Sudeste & $-0,10327$ & 1,80831 & $-0,46611$ & 1,01917 & 0,44042 & 0,50957 & 58,13 & A \\
\hline Paula Freitas & Sudeste & $-0,43454$ & 0,95593 & 2,03886 & 0,71628 & $-0,02370$ & 0,50853 & 58,10 & A \\
\hline Santa Helena & Oeste & 1,76014 & $-0,33567$ & 0,25964 & 0,36957 & $-0,88372$ & 0,50362 & 57,96 & A \\
\hline Inácio Martins & C.Sul & 0,01311 & 1,37130 & 1,51869 & $-0,27255$ & $-0,14448$ & 0,49841 & 57,81 & A \\
\hline Tunas do Paraná & RMC & $-0,98017$ & 2,99757 & 1,96917 & $-1,75040$ & 0,81154 & 0,49259 & 57,65 & A \\
\hline Ventania & C.Oriental & $-0,63405$ & 0,51152 & 1,44033 & 1,52463 & 0,93719 & 0,48926 & 57,55 & A \\
\hline Salto do Lontra & Sudoeste & 0,72360 & 1,12216 & 0,10049 & 0,14053 & $-0,36861$ & 0,48693 & 57,49 & A \\
\hline Rebouças & Sudeste & 1,21669 & 0,96023 & $-1,03642$ & 0,93619 & $-0,94241$ & 0,48446 & 57,42 & A \\
\hline Ivaí & Sudeste & 0,71013 & 1,55409 & $-1,10573$ & 0,74695 & $-0,49033$ & 0,46365 & 56,82 & M \\
\hline Bom Jesus do Sul & Sudoeste & $-0,57390$ & 2,83147 & $-0,06880$ & 0,01267 & 0,16584 & 0,45605 & 56,61 & M \\
\hline Laranjal & C.Sul & $-0,80361$ & 3,17630 & $-0,68904$ & 0,39307 & 0,49313 & 0,45592 & 56,60 & M \\
\hline Marilândia do Sul & N.Central & $-0,06127$ & 0,12583 & 1,00507 & 1,37292 & 0,48137 & 0,44372 & 56,26 & M \\
\hline Três Barras do PR & Oeste & 0,28483 & 0,84412 & 0,69095 & 0,42449 & $-0,19998$ & 0,43838 & 56,10 & M \\
\hline $\begin{array}{l}\text { Cruzeiro do } \\
\text { Iguaçu }\end{array}$ & Sudoeste & $-0,47429$ & 0,64285 & 3,01922 & $-0,45535$ & 0,20487 & 0,42929 & 55,84 & M \\
\hline Cerro Azul & RMC & 0,43058 & 2,64387 & 0,08487 & $-1,57317$ & $-0,64540$ & 0,42758 & 55,80 & M \\
\hline Reserva & C.Oriental & 0,77743 & 1,80202 & $-1,03295$ & $-0,13302$ & $-0,57809$ & 0,40580 & 55,18 & M \\
\hline Mallet & Sudeste & 0,34680 & 1,10467 & $-0,31544$ & 0,76709 & $-0,22225$ & 0,40531 & 55,16 & M \\
\hline Palmital & C.Sul & 0,42189 & 2,12683 & $-1,04821$ & 0,03080 & $-0,41989$ & 0,40252 & 55,08 & M \\
\hline Mamborê & C.Ocidental & 0,79596 & $-0,72419$ & 1,37030 & 0,64490 & $-0,23212$ & 0,39701 & 54,93 & M \\
\hline $\begin{array}{l}\text { S.Antonio } \\
\text { Sudoeste }\end{array}$ & Sudoeste & 0,86713 & 0,45303 & $-0,19183$ & 0,31648 & $-0,10785$ & 0,39484 & 54,86 & M \\
\hline
\end{tabular}




\begin{tabular}{|c|c|c|c|c|c|c|c|c|c|c|}
\hline $\begin{array}{l}\text { Assis } \\
\text { Chateaubriand }\end{array}$ & Oeste & 1,87174 & $-1,23918$ & 0,47794 & 0,18259 & $-0,47279$ & 0,39463 & 54,86 & $\mathrm{M}$ & 76 \\
\hline Rio Negro & RMC & 1,16208 & 0,47514 & 0,25448 & $-0,47613$ & $-0,55863$ & 0,39350 & 54,83 & $\mathrm{M}$ & 77 \\
\hline $\begin{array}{l}\text { N.Esperança } \\
\text { Sudoes }\end{array}$ & Sudoeste & $-0,05113$ & 1,39052 & 1,20594 & $-0,22578$ & $-0,52610$ & 0,39088 & 54,75 & $\mathrm{M}$ & 78 \\
\hline Enéas Marques & Sudoeste & 0,04022 & 1,03579 & 1,43653 & $-0,18364$ & $-0,50674$ & 0,38795 & 54,67 & M & 79 \\
\hline $\begin{array}{l}\text { Flor da Serra } \\
\text { do Sul }\end{array}$ & Sudoeste & $-0,36927$ & 1,68714 & 0,74579 & 0,41694 & $-0,43881$ & 0,38757 & 54,66 & $\mathrm{M}$ & 80 \\
\hline Tijucas do Sul & RMC & 0,84280 & 1,62620 & 0,24871 & $-1,85057$ & $-0,22090$ & 0,37217 & 54,22 & M & 81 \\
\hline Mandirituba & RMC & 0,67239 & 1,20789 & 0,23849 & $-0,66371$ & $-0,51060$ & 0,36868 & 54,12 & $\mathrm{M}$ & 2 \\
\hline Marquinho & C.Sul & $-0,48637$ & 2,38571 & $-0,91066$ & 0,40816 & 0,63021 & 0,36755 & 54,09 & M & 33 \\
\hline Nova Aurora & Oeste & 1,11500 & $-0,94756$ & 1,90764 & $-0,01196$ & $-0,82379$ & 0,36525 & 54,02 & $\mathrm{M}$ & 34 \\
\hline Planalto & Sudoeste & 1,13798 & 0,24012 & $-0,81768$ & 1,00445 & $-0,84657$ & 0,354107 & 53,70 & $\mathrm{M}$ & 5 \\
\hline Maringá & N.Central & 1,20771 & $-1,16022$ & $-2,63884$ & 1,13147 & 3,75014 & 0,353663 & 53,69 & M & 36 \\
\hline Apucarana & N.Central & 0,97065 & $-0,56591$ & $-0,98870$ & 0,83160 & 1,43913 & 0,343898 & 53,41 & M & 37 \\
\hline Quedas do Iguaçu & C.Sul & 0,77104 & 0,43202 & $-0,60508$ & 0,57455 & $-0,02078$ & 0,343799 & 53,41 & M & 38 \\
\hline Rolândia & N.Central & 0,95617 & $-1,24426$ & 0,48553 & 0,20647 & 1,56317 & 0,343207 & 53,39 & $\mathrm{M}$ & 39 \\
\hline São João & Sudoeste & 0,69662 & $-0,19406$ & $-0,15853$ & 1,68735 & $-0,77783$ & 0,330543 & 53,03 & M & 0 \\
\hline Araucária & RMC & 1,03489 & 0,04892 & $-0,47970$ & $-0,62513$ & 1,14001 & 0,32230 & 52,80 & M & 91 \\
\hline Maripá & Oeste & $-0,04005$ & $-0,41382$ & 2,39057 & 0,60780 & $-0,54162$ & 0,30868 & 52,41 & $\mathrm{M}$ & 2 \\
\hline Paulo Frontin & Sudeste & $-0,16733$ & 1,04508 & 0,28603 & 0,78188 & $-0,36997$ & 0,301575 & 52,21 & M & 3 \\
\hline Realeza & Sudoeste & 0,43452 & $-0,06959$ & 0,53412 & 0,64938 & $-0,15405$ & 0,298268 & 52,12 & M & 4 \\
\hline Palmas & C.Sul & $-0,05667$ & 0,12052 & $-0,04188$ & 1,47671 & 0,53582 & 0,297388 & 52,09 & $\mathrm{M}$ & 5 \\
\hline S.Pedro do Iguaçu & Oeste & $-0,06078$ & $-0,43142$ & 1,13301 & 1,58975 & $-1,15986$ & 0,294101 & 52,00 & M & 6 \\
\hline Mariópolis & Sudoeste & $-0,21579$ & 0,01676 & 0,93270 & 1,43404 & $-0,11681$ & 0,291665 & 51,93 & $\mathrm{M}$ & 7 \\
\hline Vitorino & Sudoeste & $-0,28206$ & 0,09581 & 1,08225 & 1,49120 & $-0,37302$ & 0,288849 & 51,85 & M & 98 \\
\hline Campo Bonito & Oeste & $-0,63799$ & 0,21453 & 1,38162 & 1,50781 & $-0,06324$ & 0,285801 & 51,76 & M & 9 \\
\hline $\begin{array}{l}\text { Fernandes } \\
\text { Pinheiro }\end{array}$ & Sudeste & $-0,88588$ & 1,79700 & 0,29059 & 1,03227 & $-0,29501$ & 0,279427 & 51,58 & $\mathrm{M}$ & 100 \\
\hline $\begin{array}{l}\text { Boa Esperança } \\
\text { Iguaç }\end{array}$ & Sudoeste & $-0,65564$ & 1,28818 & 1,64169 & 0,15400 & $-0,66134$ & 0,278876 & 51,56 & $\mathrm{M}$ & 01 \\
\hline $\begin{array}{l}\text { Sta.Izabel } \\
\text { do Oeste }\end{array}$ & Sudoeste & 0,67469 & 0,08421 & $-0,17104$ & 0,90130 & $-0,68362$ & 0,272925 & 51,39 & $\mathrm{M}$ & 102 \\
\hline Ubiratã & C.Ocidental & 0,41174 & $-0,75711$ & 0,40421 & 0,59031 & 1,17058 & 0,269010 & 51,28 & M & 103 \\
\hline Bituruna & Sudeste & 0,58342 & 0,95286 & 0,64631 & $-1,69936$ & 0,14386 & 0,266962 & 51,22 & M & 104 \\
\hline S.Jorge d'Oeste & Sudoeste & 0,12293 & 0,50137 & 0,52412 & 0,26238 & $-0,12762$ & 0,263848 & 51,14 & M & 105 \\
\hline Colombo & RMC & 0,48151 & $-0,35920$ & 1,38130 & $-2,69427$ & 3,05873 & 0,261041 & 51,06 & $\mathrm{M}$ & 106 \\
\hline Diamante do Sul & Oeste & $-1,14966$ & 2,23622 & $-0,03300$ & 0,71542 & 0,24594 & 0,254891 & 50,88 & M & 107 \\
\hline Mato Rico & C.Sul & $-1,42139$ & 3,18107 & $-0,86403$ & 0,86250 & 0,16353 & 0,254671 & 50,87 & M & 8 \\
\hline Pérola do Oeste & Sudoeste & 0,02277 & 0,64745 & $-0,38089$ & 1,02857 & $-0,01993$ & 0,24925 & 50,72 & $\mathrm{M}$ & 109 \\
\hline Itapejara do Oeste & Sudoeste & 0,19392 & $-0,07036$ & 0,42102 & 1,16352 & $-0,42099$ & 0,246552 & 50,64 & M & 10 \\
\hline Contenda & RMC & 0,26217 & 1,19857 & $-0,59395$ & $-0,23832$ & 0,09388 & 0,235372 & 50,33 & $\mathrm{M}$ & 111 \\
\hline Manoel Ribas & N.Central & 0,61719 & 0,40960 & $-0,27735$ & 0,36218 & $-0,60493$ & 0,235371 & 50,33 & M & 112 \\
\hline Missal & Oeste & 1,21115 & $-0,39325$ & 0,21446 & 0,06265 & $-1,03799$ & 0,233044 & 50,26 & M & \\
\hline Tomazina & N.Pioneiro & $-0,52555$ & 1,57151 & $-0,11443$ & $-1,36030$ & 2,31219 & 0,232094 & 50,23 & $\mathrm{M}$ & 114 \\
\hline
\end{tabular}




\begin{tabular}{|c|c|c|c|c|c|c|c|c|c|}
\hline rapongas & N.Central & 0,71986 & $-1,06070$ & $-0,06338$ & 0,69252 & 0,98334 & $0,22086949,91$ & M & 5 \\
\hline Rondon & Noroeste & $-0,91216$ & $-0,0679$ & 1,01558 & $-0,30848$ & 3,23272 & $0,20823749,55$ & $M$ & 116 \\
\hline $\begin{array}{l}\text { oa Ventura } \\
\text { Roqu }\end{array}$ & C.sul & $-0,36110$ & 1,28214 & $-0,34159$ & 1,05188 & $-0,60914$ & $0,20105349,35$ & M & \\
\hline Salgado Filho & Sudoeste & $-0,20167$ & 1,64752 & 1,01486 & $-1,67426$ & $-0,05847$ & $0,19939849,30$ & M & 8 \\
\hline Nova Prata Iguaçu & Sudoeste & 0,25950 & 0,10458 & 0,71331 & 0,31071 & $-0,63376$ & $0,19610149,21$ & M & 9 \\
\hline Reserva do Iguaçu & C.Sul & $-0,90983$ & 0,65398 & 0,76688 & 1,18324 & 0,33615 & $0,19282849,11$ & M & 0 \\
\hline Matelândia & Oeste & 0,26401 & $-0,76700$ & 0,85409 & 1,16582 & $-0,36899$ & $0,19024949,04$ & M & \\
\hline Campo do Tenente & RMC & $-0,45475$ & 0,45832 & 1,63136 & $-0,04889$ & $-0,14199$ & $0,19014149,04$ & M & \\
\hline Barracão & Sudoeste & $-0,21313$ & 1,08889 & $-0,03270$ & $-0,45714$ & 0,72228 & $0,18606348,92$ & M & \\
\hline Turvo & C.Sul & 0,61821 & 1,22107 & $-1,18294$ & $-0,09885$ & $-0,78812$ & $0,17712348,67$ & M & 124 \\
\hline Corbélia & Oeste & 0,38341 & $-1,03675$ & 1,26349 & 0,82309 & $-0,41675$ & $0,17654648,65$ & $M$ & \\
\hline $\begin{array}{l}\text { Serranópolis } \\
\text { Iguaçu }\end{array}$ & Oeste & 0,02559 & $-0,25131$ & 1,07185 & 1,22000 & $-1,12963$ & $0,17650648,65$ & M & \\
\hline Terra Roxa & Oeste & 0,66481 & $-0,66212$ & 0,45630 & 0,39765 & $-0,28772$ & $0,17374148,57$ & $M$ & \\
\hline $\begin{array}{l}\text { Ouro Verde } \\
\text { do Oeste }\end{array}$ & Oeste & $-0,38401$ & $-0,51314$ & 1,63258 & 1,03284 & $-0,11003$ & $0,16798748,41$ & M & \\
\hline Quatro Pontes & Oeste & $-0,24456$ & $-0,36982$ & 2,43859 & 0,12660 & $-0,69737$ & $0,16385348,29$ & M & \\
\hline Ivaiporã & N.central & 1,57822 & $-0,58027$ & $-0,63013$ & $-0,28100$ & $-0,71859$ & $0,16272748,26$ & M & 0 \\
\hline Laranjeiras do Sul & C.Sul & 0,79312 & 0,31569 & $-0,71698$ & $-0,16079$ & $-0,26609$ & $0,16214748,24$ & M &  \\
\hline Clevelândia & C.Sul & $-0,03221$ & $-0,26985$ & 0,16083 & 1,31229 & $-0,02671$ & $0,15571648,06$ & M & \\
\hline Céu Azul & Oeste & 0,21001 & $-0,75748$ & 1,51785 & 0,38494 & $-0,42584$ & $0,15320647,99$ & M & \\
\hline Leópolis & N.Pioneiro & $-0,73948$ & 0,28447 & 1,15345 & 0,42192 & 0,64482 & $0,14873947,86$ & M & 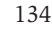 \\
\hline General Carneiro & Sudeste & 0,08002 & 0,24945 & 2,60821 & $-2,35567$ & 0,06644 & $0,14651547,80$ & M & \\
\hline Medianeira & Oeste & 1,00058 & $-1,28185$ & 0,30681 & 0,28108 & 0,03891 & $0,14450547,74$ & M & \\
\hline $\begin{array}{l}\text { Espigão Alto } \\
\text { Iguaçu }\end{array}$ & C.Sul & $-0,29880$ & 0,96372 & 0,15329 & 0,43973 & $-0,53588$ & $0,14410947,73$ & M & \\
\hline $\begin{array}{l}\text { a. Maria } \\
\text { Oeste }\end{array}$ & C.Sul & 0,25251 & 1,36233 & $-1,22872$ & 0,21886 & $-0,68014$ & $0,14201847,67$ & M & \\
\hline Porto Amazonas & RMC & $-1,04136$ & 0,13191 & 0,94514 & 1,24931 & 0,89530 & $0,13952247,60$ & M & \\
\hline Rio Branco do Sul & RMC & 0,54609 & 1,82116 & $-0,78803$ & $-1,90905$ & $-0,25893$ & $0,13513647,47$ & M & 40 \\
\hline Tupãssi & Oeste & $-0,06751$ & $-0,86766$ & 1,18085 & 0,97411 & 0,07709 & $0,131814 \quad 47,46$ & M & \\
\hline Luiziana & C.Ocidental & $-0,29825$ & $-0,50173$ & 1,57981 & 0,88899 & $-0,41880$ & $0,13022247,33$ & M & \\
\hline Nova Tebas & N.Central & $-0,31813$ & 1,66866 & $-0,77578$ & $-0,06607$ & $-0,08984$ & $0,12184547,09$ & M & \\
\hline Pranchita & Sudoeste & $-0,21276$ & 0,12375 & 0,20632 & 1,04676 & $-0,30654$ & $0,115400 \quad 46,91$ & M & \\
\hline Nova Santa Rosa & Oeste & 0,05022 & $-0,43792$ & 1,40249 & 0,35907 & $-0,70325$ & $0,11475946,89$ & M & \\
\hline Ampere & Sudoeste & 0,35065 & 0,11697 & $-0,17851$ & 0,20422 & $-0,27336$ & $0,11273246,83$ & M & \\
\hline Balsa Nova & RMC & $-0,28290$ & 1,19581 & $-0,55320$ & 0,04721 & 0,12862 & $0,10790946,70$ & M & \\
\hline Goioerê & C.Ocidental & $-0,20560$ & $-0,43495$ & $-0,53518$ & 0,71770 & 1,96822 & $0,10105646,50$ & M & \\
\hline $\begin{array}{l}\text { Bela Vista do } \\
\text { Caroba }\end{array}$ & Sudoeste & $-0,90542$ & 1,01379 & $-0,05010$ & 0,83151 & 0,43045 & $0,09972146,46$ & M & \\
\hline Rio Branco do Ivaí & N.Central & $-0,94134$ & 1,92594 & 0,55870 & $-1,41540$ & 0,87571 & $0,09627846,37$ & M & \\
\hline Sulina & Sudoeste & $-0,85013$ & 0,54962 & 0,45455 & 1,03593 & 0,10636 & $0,08748446,12$ & M & \\
\hline Mauá da Serra & N.Central & $-1,11886$ & 0,06347 & $-0,05020$ & 1,82142 & 1,35405 & $0,08265345,98$ & M & \\
\hline Porto Vitória & Sudeste & $-0,58487$ & 0,85238 & 1,39555 & $-1,79088$ & 1,09840 & $0,07853245,86$ & M & \\
\hline Roncador & C.Ocidental & 0,20812 & 0,28024 & $-0,90285$ & 1,08550 & $-0,63906$ & $0,07670545,81$ & M & \\
\hline
\end{tabular}




\begin{tabular}{|c|c|c|c|c|c|c|c|c|c|c|}
\hline eiro & C.Sul & $-0,49018$ & 1,27284 & $-0,66999$ & 1,02695 & $-0,78938$ & 0,076543 & 45,80 & M & 5 \\
\hline $\begin{array}{l}\text { Pinhal de São } \\
\text { Bento }\end{array}$ & ido & $-0,86818$ & 0,952 & 1,03 & $-0,17$ & 0,101 & 0,07 & 45 & 1 & \\
\hline $\begin{array}{l}\text { Campina do } \\
\text { Simão }\end{array}$ & Sul & $-0,79832$ & 1,04086 & 0,30606 & 0,50948 & $-0,16464$ & 0,075822 & 45,78 & M & \\
\hline Piên & RMC & 0,52974 & 1,00578 & 0,35772 & $-1,82586$ & $-0,84547$ & 0,072602 & 45,69 & M & 58 \\
\hline Curiúva & N.Pioneiro & $-0,15623$ & 0,78711 & 0,41803 & $-0,40758$ & $-0,47188$ & 0,070840 & 45,64 & M & 59 \\
\hline Jardim Olinda & Noroeste & $-0,97133$ & $-0,25431$ & 2,08476 & 0,23788 & 0,60913 & 0,067868 & 45,56 & M & \\
\hline Virmond & C.Sul & $-0,49518$ & 1,07268 & 0,01084 & 0,10342 & $-0,24648$ & 0,063163 & 45,42 & $\Lambda$ & \\
\hline Agudos do Sul & RMC & $-0,08630$ & 1,52672 & 0,38733 & $-1,70537$ & $-0,39761$ & 0,062546 & 45,41 & M & 52 \\
\hline Sabáudia & N.Central & $-0,57557$ & $-0,49337$ & 0,30763 & 1,49028 & 0,66514 & 0,060 & 45,35 & M & 3 \\
\hline Tamarana & N.Central & $-0,14385$ & 0,07623 & $-0,29416$ & 1,21340 & -0, & 0,0 & 5,28 & M & \\
\hline Marialva & N.Central & 1,16003 & $-1,18799$ & $-1,07298$ & 0,64016 & 0,06148 & 0,054154 & 45,17 & M & 5 \\
\hline Manfrinópolis & Sudoeste & $-0,51978$ & 1,90033 & 0,45974 & $-1,47191$ & $-0,39163$ & 0,050480 & 45,06 & M & \\
\hline $\begin{array}{l}\text { Vera Cruz } \\
\text { do Oeste }\end{array}$ & este & $-0,23406$ & $-0,41205$ & 0,45691 & 1,13669 & $-0,29664$ & 0,0436 & 44,87 & M & \\
\hline Novo Itacolomi & N.Central & $-0,86988$ & 1,20943 & 0,11480 & 0,00755 & 0,34126 & 0,042970 & 44,85 & M & \\
\hline Ibema & Oeste & $-0,73761$ & $-0,48588$ & 1,12600 & 1,07783 & 0,31563 & 0,033323 & 44,57 & M & 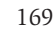 \\
\hline Boa Esperança & C.Ocidental & $-0,37904$ & $-0,61609$ & 1,62625 & 0,65229 & $-0,55406$ & 0,031503 & 44,52 & M & \\
\hline Anahy & Oeste & $-0,96328$ & $-0,11169$ & 1,28028 & 0,82600 & 0,33979 & 0,030761 & 44,50 & M & \\
\hline Campina da Lagoa & C.Ocidental & 0,34268 & $-0,55993$ & $-0,55665$ & 0,87859 & $-0,06692$ & 0,027101 & 44,40 & M & 2 \\
\hline Formosa do Oeste & Oeste & 0,05939 & $-0,71135$ & $-0,42629$ & 1,36267 & 0,15568 & 0,022296 & 44,26 & M & \\
\hline Itaperuçu & RMC & $-0,52653$ & 1,77773 & 0,14642 & $-1,83339$ & 0,46493 & 0,019130 & 44,17 & M & \\
\hline Platina & N.Pioneiro & 1,18443 & $-0,24646$ & $-0,97483$ & $-0,57285$ & $-0,67100$ & 0,0107 & 43,93 & M & \\
\hline $\begin{array}{l}\text { Cap Leônidas } \\
\text { Marqu }\end{array}$ & Oeste & 0,03641 & $-0,52695$ & 0,63941 & 0,2 & -0 & 0,0 & 7 & М & \\
\hline Campo Largo & RMC & 0,05834 & 0,47399 & $-0,75407$ & $-0,52989$ & 0,70287 & 0,0079 & 43,85 & M & \\
\hline Mercedes & Oeste & 0,12657 & $-0,02446$ & 0,30817 & 0,21652 & $-0,94842$ & 0,003607 & 43,73 & M & \\
\hline Cianorte & Noroeste & 0,99694 & $-0,90568$ & $-0,76091$ & $-0,36849$ & 0,42898 & 0,001822 & 43,68 & M & 9 \\
\hline Nova Cantu & C.Ocidental & $-0,30609$ & 0,09216 & $-0,76760$ & 1,51458 & $-0,39667$ & $-0,01887$ & 43,09 & B & \\
\hline Foz do Jordão & C.Sul & $-0,76244$ & $-0,17110$ & 0,63195 & 0,94977 & 0,17530 & $-0,02145$ & 43,02 & B & \\
\hline $\begin{array}{l}\text { Sta.Tereza } \\
\text { do Oeste }\end{array}$ & Oeste & $-0,52919$ & $-0,92948$ & 1,36922 & 0,77287 & 0,14608 & $-0,02575$ & 42,89 & B & \\
\hline Iretama & C.Ocidental & $-0,39397$ & 0,90276 & $-0,90131$ & 0,24507 & 0,04962 & $-0,03040$ & 42,76 & B & \\
\hline Bocaiúva do Sul & RMC & $-0,09857$ & 1,30812 & 0,14039 & $-1,88456$ & $-0,21985$ & $-0,03671$ & 42,58 & B & \\
\hline São Pedro do Ivaí & N.Central & $-0,73048$ & $-0,31662$ & $-0,16920$ & 1,04704 & 1,14795 & $-0,03826$ & 42,54 & B & 5 \\
\hline Guapirama & N.Pioneiro & $-0,50778$ & $-0,29014$ & 2,27883 & $-1,10276$ & $-0,00658$ & $-0,03847$ & 42,53 & B & \\
\hline Jesuítas & Oeste & 0,03733 & $-0,62164$ & $-0,37549$ & 0,85647 & 0,12278 & $-0,03958$ & 42,50 & B & \\
\hline Sengés & C.Oriental & $-0,14983$ & $-0,06575$ & 0,00932 & 0,29372 & $-0,17989$ & $-0,03977$ & 42,49 & B & \\
\hline $\begin{array}{lll}\text { Entre } & \text { Rios do } \\
\text { Oeste } & & \end{array}$ & Oeste & $-0,50111$ & $-0,56557$ & 1,47786 & 0,03520 & 0,05291 & $-0,04332$ & 42,39 & B & \\
\hline Diamante do Oeste & Oeste & $-0,77364$ & 0,23937 & 0,46686 & 0,75356 & $-0,28297$ & $-0,04665$ & 42,30 & $\mathrm{~B}$ & 190 \\
\hline Cambira & N.Central & $-0,66178$ & 0,18199 & $-0,22715$ & 0,79757 & 0,36924 & $-0,04736$ & 42,28 & B & \\
\hline Adrianópolis & RMC & $-0,37342$ & 1,87291 & $-0,37345$ & $-1,45734$ & $-0,52328$ & $-0,05565$ & 42,04 & $\mathrm{~B}$ & \\
\hline Alto Paraíso & Noroeste & $-0,75822$ & $-0,14567$ & 1,85465 & $-0,30967$ & $-0,18971$ & $-0,05743$ & 41,99 & B & \\
\hline
\end{tabular}




\begin{tabular}{|c|c|c|c|c|c|c|c|c|c|c|}
\hline $\begin{array}{l}\text { Boa Vista } \\
\text { Aparecida }\end{array}$ & Oeste & $-0,44300$ & 0,16064 & $-0,42206$ & 0,90249 & $-0,15558$ & $-0,05891$ & 41,95 & B & 194 \\
\hline $\begin{array}{l}\text { Saudade do } \\
\text { Iguaçu }\end{array}$ & Sudoeste & $-0,81419$ & 0,45201 & 0,07125 & 0,57380 & 0,07111 & $-0,06085$ & 41,89 & B & 195 \\
\hline Quarto Centenário & C.Ocidental & $-0,58507$ & $-0,03106$ & 0,45999 & 0,58386 & $-0,19596$ & $-0,06125$ & 41,88 & 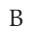 & 196 \\
\hline $\begin{array}{l}\text { S. Jerônimo } \\
\text { da Serra }\end{array}$ & N.Pioneiro & 0,05349 & 0,63746 & $-1,88728$ & 0,74556 & $-0,28184$ & $-0,06304$ & 41,83 & B & 197 \\
\hline Juranda & C.Ocidental & 0,10050 & $-0,82819$ & 0,29647 & 0,43076 & $-0,21271$ & $-0,06371$ & 41,81 & B & 198 \\
\hline Cambé & N.Central & 0,47820 & $-1,02293$ & $-0,81444$ & 0,28715 & 0,75042 & $-0,06489$ & 41,78 & 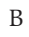 & 9 \\
\hline Guaíra & Oeste & 0,57715 & $-0,68738$ & $-0,30506$ & $-0,26016$ & $-0,12354$ & $-0,06678$ & 41,73 & B & 200 \\
\hline Peabiru & C.Ocidental & 0,07867 & $-0,89450$ & $-0,31453$ & 0,80445 & 0,24023 & $-0,07087$ & 41,61 & B & 201 \\
\hline Braganey & Oeste & $-0,40717$ & $-0,32202$ & 0,01145 & 1,39684 & $-0,66917$ & $-0,07152$ & 41,59 & B & 2 \\
\hline Fênix & C.Ocidental & $-0,81273$ & $-0,24379$ & 0,64897 & 0,69055 & 0,25677 & $-0,08218$ & 41,29 & ? & 03 \\
\hline Faxinal & N.Central & $-0,31793$ & $-0,06201$ & $-0,56351$ & 0,97386 & $-0,19142$ & $-0,08370$ & 41,24 & B & 204 \\
\hline Jaguariaíva & C.Oriental & $-0,29314$ & 0,63001 & $-1,07684$ & 0,21756 & 0,09693 & $-0,08490$ & 41,21 & B & J \\
\hline Jacarezinho & N.Pioneiro & 0,69098 & $-0,44490$ & $-0,39352$ & $-0,95096$ & $-0,07245$ & $-0,08984$ & 41,07 & 5 & 6 \\
\hline S.Jorge do Ivaí & N.Central & $-0,14303$ & $-0,87585$ & 1,27824 & $-0,03051$ & $-0,40912$ & $-0,09287$ & 40,98 & B & 207 \\
\hline Astorga & N.Central & 0,38051 & $-0,98204$ & $-0,38665$ & 0,19972 & 0,25538 & $-0,09341$ & 40,97 & B & 8 \\
\hline Rio Bom & N.Central & $-0,80168$ & 0,33254 & 0,13456 & 0,38289 & 0,13084 & $-0,09565$ & 40,90 & 3 & 209 \\
\hline Centenário do Sul & N.Central & $-0,83514$ & 0,11440 & $-0,50701$ & 0,18297 & 1,69893 & $-0,09776$ & 40,84 & B & 10 \\
\hline Lindoeste & Oeste & $-0,60449$ & 0,05360 & $-0,16292$ & 0,90470 & $-0,19530$ & $-0,09954$ & 40,79 & B & 211 \\
\hline Altamira do PR & C.Ocidental & $-0,79051$ & 1,39730 & $-1,21121$ & 0,50837 & $-0,29738$ & $-0,10368$ & 40,68 & 3 & 212 \\
\hline Califórnia & N.Central & $-0,54966$ & 0,48769 & $-0,19116$ & $-0,37573$ & 0,37668 & $-0,11716$ & 40,29 & B & \\
\hline São João do Ivaí & N.Central & 0,10206 & $-0,57981$ & $-0,78400$ & 1,10041 & $-0,57283$ & $-0,12239$ & 40,14 & B & 4 \\
\hline Cons. Mairinck & N.Pioneiro & $-0,58373$ & $-0,02849$ & 1,64593 & $-1,08171$ & $-0,17904$ & $-0,12550$ & 40,05 & B & 15 \\
\hline Rosário do Ivaí & N.Central & $-0,15297$ & 1,07538 & $-0,02668$ & $-1,66320$ & $-0,44758$ & $-0,12786$ & 39,99 & 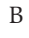 & \\
\hline $\begin{array}{l}\text { Engenheiro } \\
\text { Beltrão }\end{array}$ & C.Ocidental & 0,02657 & $-0,88298$ & $-0,08780$ & 0,59770 & $-0,14209$ & $-0,12828$ & 39,97 & B & \\
\hline Pinhais & RMC & $-1,54533$ & $-0,00944$ & $-0,25052$ & $-1,91209$ & 5,89834 & $-0,13045$ & 39,91 & & \\
\hline S. Manoel do PR & Noroeste & $-1,16171$ & 0,43341 & 0,92532 & 0,41946 & $-0,46658$ & $-0,13315$ & 39,84 & B & \\
\hline Ramilândia & Oeste & $-1,08825$ & 0,25680 & 0,31030 & 1,07136 & $-0,36104$ & $-0,13337$ & 39,83 & 3 & 20 \\
\hline Farol & C.Ocidental & $-0,69297$ & $-0,38872$ & 0,51140 & 1,11666 & $-0,60046$ & $-0,13625$ & 39,75 & B & \\
\hline Santa Lúcia & Oeste & $-0,78432$ & $-0,24803$ & 0,23629 & 1,07903 & $-0,22058$ & $-0,13877$ & 39,68 & B & \\
\hline Barra do Jacaré & N.Pioneiro & $-0,61614$ & $-0,54586$ & 1,48070 & 0,22412 & $-0,69088$ & $-0,13908$ & 39,67 & 3 & 3 \\
\hline Porecatu & N.Central & $-0,79053$ & $-0,03185$ & $-0,47525$ & 0,19734 & 1,44385 & $-0,13977$ & 39,65 & B & 224 \\
\hline Sapopema & N.Pioneiro & $-0,46742$ & 1,62745 & $-0,46573$ & $-1,65692$ & $-0,17724$ & $-0,14566$ & 39,48 & D & \\
\hline Piraquara & RMC & $-0,24703$ & 0,44920 & $-0,74062$ & $-1,52671$ & 1,56707 & $-0,14627$ & 39,46 & B & \\
\hline Iguatu & Oeste & $-1,01496$ & $-0,25198$ & 0,55070 & 1,14499 & $-0,16010$ & $-0,14811$ & 39,41 & B & 17 \\
\hline Jardim Alegre & N.Central & 0,04877 & 0,04185 & $-0,98370$ & 0,44063 & $-0,68877$ & $-0,14982$ & 39,36 & B & \\
\hline $\begin{array}{l}\text { Rancho Alegre } \\
\text { Oeste }\end{array}$ & C.Ocidental & $-0,79178$ & $-0,37881$ & 0,78473 & 0,44678 & $-0,05778$ & $-0,16027$ & 39,06 & P & \\
\hline Miraselva & N.Central & $-1,12395$ & $-0,48904$ & 0,87227 & 0,13121 & 1,320114 & $-0,16132$ & 39,03 & P & \\
\hline Cruzeiro do Sul & Noroeste & $-0,52832$ & $-0,47941$ & 1,22335 & $-0,11991$ & $-0,46866$ & $-0,16267$ & 39,00 & B & \\
\hline União da Vitória & Sudeste & 0,15514 & $-0,12860$ & $-0,83130$ & $-0,27915$ & $-0,10503$ & $-0,16811$ & 38,84 & P & 232 \\
\hline Altônia & Noroeste & 0,74300 & $-0,37838$ & $-0,93635$ & $-0,65756$ & $-0,64083$ & $-0,16973$ & 38,80 & B & \\
\hline '́ & C.Oriental & $-0,42492$ & 0,49081 & $-0,98297$ & 0,41964 & $-0,36573$ & $-0,17057$ & 38,77 & 3 & \\
\hline
\end{tabular}




\begin{tabular}{|c|c|c|c|c|c|c|c|c|c|c|}
\hline Ivaí & N.Central & $-1,14901$ & 0,76036 & 0,26131 & 0,43684 & $-0,55892$ & $-0,17160$ & 38,74 & $\mathrm{~B}$ & 5 \\
\hline ândia do Sul & Noroeste & $-1,03774$ & 0,08031 & 0,41290 & 0,72419 & $-0,19002$ & $-0,17256$ & 38,71 & B & \\
\hline $\begin{array}{l}\text { S.José da Boa } \\
\text { Vista }\end{array}$ & eiro & $-0,47$ & 0,70914 & 056 & $-0,61$ & $-0,54$ & $-0,1$ & 38 & B & \\
\hline Nova Esperança & N.Central & 0,50318 & $-1,09177$ & $-0,81187$ & 0,15346 & 0,06028 & $-0,17744$ & 38,58 & B & \\
\hline Bandeirantes & N.Pioneiro & 0,67332 & $-0,47419$ & $-1,14775$ & $-0,65786$ & $-0,07955$ & $-0,17970$ & 38,51 & B & \\
\hline Cruzmaltina & N.Central & $-0,85069$ & 0,12324 & 0,39048 & 0,66659 & $-0,74927$ & $-0,18188$ & 38,45 & B & \\
\hline Corumbataí do Sul & C.Ocidental & $-0,74776$ & 0,56363 & $-0,72829$ & 0,59212 & $-0,30460$ & $-0,18647$ & 38,32 & B & \\
\hline Serta & N.Central & 0,09383 & $-0,97651$ & $-0,24922$ & 0,24124 & 0,01363 & $-0,18930$ & 38,24 & B & \\
\hline $\begin{array}{l}\text { Querência do } \\
\text { Norte }\end{array}$ & Noroeste & 0,06298 & $-0,20126$ & $-0,66848$ & $-0,18954$ & $-0,227$ & -0 , & 38,22 & B & \\
\hline Para & te & 48 & 147 & $-0,51118$ & 707 & 3461 & -0 & 7 & B & \\
\hline Araruna & C.Ocidental & $-0,01578$ & $-0,72781$ & $-0,56688$ & 0,86160 & $-0,55594$ & $-0,19501$ & 38,08 & B & \\
\hline Carlópolis & N.Pioneiro & 0,43360 & 0,05773 & 0,29885 & $-2,07295$ & $-0,65119$ & $-0,19678$ & 38,03 & B & \\
\hline Pitangueiras & N.Central & $-0,97354$ & $-0,51969$ & 0,50422 & 0,81058 & 0,2 & -0 & 37,93 & B & \\
\hline rama & Noroeste & 1,46778 & $-1,45082$ & $-0,75649$ & $-1,04405$ & $-0,66055$ & $-0,20209$ & 37,87 & 3 & \\
\hline Borrazópolis & N.Central & $-0,31362$ & $-0,46323$ & $-0,80115$ & 1,11998 & $-0,34295$ & $-0,20653$ & 37,75 & B & \\
\hline Cornélio Procópio & N.Pioneiro & 0,62833 & $-1,10943$ & $-0,81729$ & $-0,39172$ & 0,19069 & $-0,2$ & 37,67 & B & \\
\hline Barbosa Ferraz & C.Ocidental & $-0,12777$ & $-0,16810$ & $-1,21704$ & 0,62894 & $-0,25519$ & $-0,21108$ & 37,62 & B & \\
\hline Quinta do Sol & C.Ocidenta & $-0,54389$ & $-0,67686$ & $-0,12067$ & 0,90899 & $-0,01255$ & $-0,21349$ & 37,55 & B & \\
\hline aguari & N.Central & $-0,19374$ & $-0,98249$ & $-0,95075$ & 0,94596 & 0,55411 & $-0,22404$ & 37,25 &  & \\
\hline Kaloré & N.Central & $-0,79806$ & $-0,30663$ & $-0,93381$ & 1,40575 & 0,35314 & $-0,22448$ & 37,24 & $\mathrm{~B}$ & \\
\hline Telêmaco Borba & C.Oriental & $-0,20461$ & $-1,00484$ & 0,99041 & $-0,65657$ & 0,01703 & $-0,23409$ & 36,96 & B & \\
\hline Ibaiti & N.Pi & 0,61689 & 0,07476 & $-0,69152$ & $-1,93967$ & 4966 & -0 , & 36,96 & B & \\
\hline Ivatuba & N.Central & $-0,71752$ & $-0,5780$ & 0,23891 & 0,78531 & $-0,21597$ & $-0,23573$ & 36,92 & B & \\
\hline Guaporema & Noroeste & $-0,78061$ & $-0,24038$ & 1,46045 & $-0,60396$ & $-0,55597$ & $-0,24111$ & 36,77 & $\mathrm{R}$ & \\
\hline Bragado & Oeste & 115 & $-0,55126$ & 0,67090 & 558 & -0 & 320 & 36,70 & D & \\
\hline Francisco Alves & Noroeste & $-0,28551$ & $-0,49185$ & $-0,21413$ & 0,38166 & $-0,52102$ & $-0,24544$ & 36,64 & B & \\
\hline Tuneiras do Oeste & Noroeste & $-0,19040$ & $-0,30329$ & $-0,59713$ & 0,26462 & $-0,50652$ & $-0,24972$ & 36,52 & 2 & \\
\hline Marumbi & N.Central & $-0,77774$ & 0,17409 & $-0,29025$ & 0,08738 & 899 & 188 & 36,46 & B & \\
\hline Floresta & N.Central & $-0,62669$ & $-0,83893$ & 0,45051 & 0,52886 & $-0,08345$ & $-0,25305$ & 36,42 & B & \\
\hline Joaquim Távora & N.Pioneiro & $-0,41311$ & 0,30024 & $-0,21174$ & $-0,91880$ & $-0,05949$ & $-0,25531$ & 36,36 & B & \\
\hline Campo Magro & RMC & $-0,50091$ & 0,88984 & $-0,28620$ & $-1,47076$ & $-0,11799$ & $-0,25733$ & 36,30 & 3 & \\
\hline Lidianópolis & N.Central & $-0,60684$ & 0,05773 & $-0,66099$ & 0,74281 & $-0,65131$ & $-0,26145$ & 36,18 & $\mathrm{~B}$ & \\
\hline Santa Inês & N.Central & $-0,70240$ & $-0,07366$ & 0,13319 & $-0,01011$ & $-0,24951$ & $-0,26209$ & 36,17 & $P$ & \\
\hline Arapuã & N.Central & $-0,81097$ & 0,47089 & $-0,46751$ & 0,48638 & $-0,81178$ & $-0,26516$ & 36,08 & $D$ & \\
\hline Iguaraçu & N.Central & $-0,61779$ & $-0,96625$ & 1,16587 & $-0,10348$ & $-0,11583$ & $-0,26532$ & 36,07 & $\mathrm{~B}$ & \\
\hline Jaguapitã & N.Central & $-0,19190$ & $-0,96545$ & 0,28722 & $-0,18957$ & $-0,05263$ & $-0,27071$ & 35,92 & D & \\
\hline Jandaia do Sul & N.Central & $-0,39292$ & $-0,60396$ & $-0,94534$ & 0,52372 & 0,53883 & $-0,27228$ & 35,88 & B & \\
\hline Alm. Tamandaré & RMC & 0,00993 & $-0,28662$ & $-0,45079$ & $-1,99104$ & 1,37332 & $-0,27510$ & 35,80 & $\mathrm{~B}$ & \\
\hline Maria Helena & Noroeste & $-0,65523$ & 0,23909 & $-0,24124$ & $-0,19416$ & $-0,33478$ & $-0,27581$ & 35,78 & $R$ & \\
\hline Lunardelli & N.Central & $-0,73009$ & $-0,09859$ & $-0,71678$ & 0,86421 & $-0,25315$ & $-0,27887$ & 35,69 & B & \\
\hline Sertaneja & N.Pioneiro & $-0,25883$ & $-0,72415$ & $-0,17070$ & $-0,50221$ & 0,59596 & $-0,28179$ & 35,61 & B & \\
\hline Wenceslau Braz & N.Pioneiro & 0,37949 & $-0,08414$ & $-0,24667$ & $-2,00799$ & $-0,32163$ & $-0,28440$ & 35,53 & B & \\
\hline Janiópolis & C.Ocidental & $-0,3007$ & $-0,53682$ & $-1,02503$ & 1,02298 & $-0,46055$ & $-0,28463$ & 35,52 & $\mathrm{~B}$ & \\
\hline
\end{tabular}




\begin{tabular}{|c|c|c|c|c|c|c|c|c|c|c|}
\hline també & N.Central & $-0,56897$ & $-0,81200$ & 0,21974 & 0,17907 & 0,19205 & $-0,28562$ & 35,50 & B & 278 \\
\hline Jundiaí do Sul & N.Pioneiro & $-0,83611$ & 0,26260 & 0,10269 & $-0,61385$ & 0,11089 & $-0,28576$ & 35,49 & B & 279 \\
\hline Primeiro de Maio & N.Central & $-0,00130$ & $-1,01950$ & $-1,14568$ & 0,82835 & $-0,03200$ & $-0,29013$ & 35,37 & B & \\
\hline Iporã & Noroeste & 0,26832 & $-0,84492$ & $-0,60638$ & $-0,08595$ & $-0,63959$ & $-0,29067$ & 35,35 & B & \\
\hline Godoy Moreira & N.Central & $-1,05416$ & 0,58533 & $-0,93643$ & 0,46470 & 0,05754 & $-0,29295$ & 35,29 & 3 & \\
\hline Ângulo & N.Central & $-0,88153$ & $-0,47962$ & $-0,15342$ & 0,37470 & 0,53902 & $-0,30258$ & 35,01 & 3 & \\
\hline Itaguajé & N.Central & $-0,91589$ & $-0,02537$ & $-0,21909$ & 0,10939 & 0,17326 & $-0,30895$ & 34,83 & B & \\
\hline Campina Gde Sul & RMC & $-0,05582$ & 0,07522 & $-0,30521$ & $-1,94942$ & 0,36720 & $-0,30958$ & 34,81 & $B$ & \\
\hline Ribeirão Claro & N.Pioneiro & 0,09958 & 0,41664 & $-0,26842$ & $-2,10067$ & $-0,55119$ & $-0,31160$ & 34,76 & & \\
\hline Assaí & N.Pioneiro & 0,33603 & $-0,69995$ & $-1,24495$ & $-0,05232$ & $-0,49334$ & $-0,31560$ & 34,64 & 3 & \\
\hline Iorretes & RMC & 0,46026 & 0,10959 & $-1,03938$ & $-1,74188$ & $-0,44631$ & $-0,316$ & 34,63 & 3 & \\
\hline om Sucesso & N.Central & $-0,61671$ & $-0,48399$ & $-0,53440$ & 0,57324 & $-0,07746$ & $-0,32177$ & 34,47 & 3 & \\
\hline Floraí & N.Central & $-0,53465$ & $-0,87961$ & 0,04129 & 0,46913 & $-0,21164$ & $-0,32280$ & 34,44 & 3 & \\
\hline Santana do Itararé & N.Pioneiro & $-0,23284$ & 0,40719 & 0,14877 & $-2,03157$ & $-0,47225$ & $-0,33679$ & 34,04 & B & \\
\hline Cambará & N.Pioneiro & 0,32841 & $-1,17670$ & $-0,39180$ & $-0,24593$ & $-0,66650$ & $-0,3$ & 33,99 & 3 & \\
\hline Grandes Rios & N.Central & $-0,24756$ & 0,43595 & $-0,46301$ & $-1,42519$ & $-0,48187$ & $-0,34106$ & 33,92 & 3 & \\
\hline Santo Inácio & N.Central & $-0,68437$ & $-0,25828$ & $-0,05295$ & $-0,40674$ & 0,10184 & $-0,34621$ & 33,77 & 3 & \\
\hline Moreira Sales & C.Ocidental & 0,15674 & $-0,75568$ & $-1,30576$ & 0,12680 & $-0,3$ & $-0,3$ & 33,67 & 3 & \\
\hline $\begin{array}{l}\text { Sta.Terezinha } \\
\text { Itaipu }\end{array}$ & Oeste & $-0,29269$ & $-1,43563$ & $-0,03920$ & 0,59944 & 1075 & -0 & 33,64 & B & \\
\hline batiá & eiro & $-0,26157$ & 0,00137 & $-1,08625$ & 168 & $-0,50789$ & $-0,3$ & 33,55 & 3 & \\
\hline Douradina & Noroeste & $-0,67796$ & $-0,30518$ & 0,15853 & $-0,36502$ & $-0,22887$ & $-0,35461$ & 33,53 & 3 & \\
\hline araíso do Norte & Noroeste & $-0,88871$ & $-0,25323$ & $-0,95344$ & 0,65302 & 0,38136 & $-0,35972$ & 33,39 & 3 & \\
\hline Santa Mariana & N.Pioneiro & $-0,01887$ & $-0,61248$ & $-0,81060$ & $-0,46311$ & $-0,10133$ & $-0,35991$ & 33,38 & 3 & 50 \\
\hline Siqueira Campos & N.Pioneiro & 0,24915 & $-0,01144$ & $-0,02918$ & $-2,33179$ & $-0,60588$ & $-0,36185$ & 33,33 & B & \\
\hline Mirador & Noroeste & $-1,07490$ & $-0,53634$ & 0,54658 & 0,38434 & $-0,25093$ & $-0,36241$ & 33,31 & B & \\
\hline Cruzeiro do Oeste & Noroeste & 0,10808 & $-0,69027$ & $-0,78105$ & $-0,47520$ & $-0,37051$ & $-0,36507$ & 33,24 & 3 & \\
\hline Mandaguaçu & N.Central & $-0,19337$ & $-1,14820$ & $-0,51593$ & 0,22762 & 0,00375 & $-0,36945$ & 33,11 & 3 & \\
\hline Terra Boa & C.Ocidental & $-0,28167$ & $-1,03388$ & $-1,02724$ & 0,78512 & $-0,01029$ & $-0,37195$ & 33,04 & B & \\
\hline Guaraqueçaba & RMC & $-0,31988$ & 1,23494 & $-1,31284$ & $-1,44110$ & $-0,88183$ & $-0,37497$ & 32,95 & $B$ & \\
\hline Bela Vista Paraíso & N.Central & $-0,15423$ & $-1,09191$ & $-0,91755$ & 0,50711 & $-0,07227$ & $-0,37558$ & 32,94 & 3 & \\
\hline Cafeara & N.Central & $-0,96266$ & $-0,08465$ & 0,16367 & $-0,29057$ & $-0,13848$ & $-0,37662$ & 32,91 & B & \\
\hline Amaporã & Noroeste & $-0,53639$ & $-0,39658$ & 1,05888 & $-1,79651$ & $-0,00045$ & $-0,37695$ & 32,90 & 3 & \\
\hline azenda Rio Gde & RMC & $-1,01214$ & $-0,94080$ & $-0,74556$ & 0,13721 & 2,20722 & $-0,37733$ & 32,89 & B & \\
\hline Guaraci & N.Central & $-0,53137$ & $-0,83217$ & 0,46262 & $-0,40111$ & $-0,21588$ & $-0,37887$ & 32,84 & B & \\
\hline São Carlos Ivaí & Noroeste & $-0,81119$ & $-0,89197$ & 0,04414 & 0,22823 & 0,40263 & $-0,37940$ & 32,83 & 3 & \\
\hline ranacity & Noroeste & $-0,62229$ & $-0,78551$ & $-0,19598$ & 0,21361 & 0,01513 & $-0,38123$ & 32,78 & B & \\
\hline Alto Piquiri & Noroeste & $-0,32843$ & $-0,71317$ & $-0,61108$ & 0,31962 & $-0,52435$ & $-0,38268$ & 32,73 & B & \\
\hline $\begin{array}{l}\text { ssé das } \\
\text { meiras }\end{array}$ & Oeste & $-0,70878$ & $-0,22466$ & $-0,04631$ & $-0,21460$ & $-0,44550$ & $-0,3832$ & 32,12 & B & \\
\hline Inajá & Noroeste & $-0,84114$ & $-0,57519$ & $-0,04776$ & 0,06133 & 0,20427 & $-0,38350$ & 32,71 & B & \\
\hline Tapira & Noroeste & $-0,41396$ & $-0,41226$ & $-0,40086$ & $-0,16693$ & $-0,54420$ & $-0,38902$ & 32,55 & 3 & \\
\hline Itaipulândia & Oeste & $-0,46655$ & $-0,79123$ & $-0,21982$ & 0,17049 & $-0,38747$ & $-0,39063$ & 32,51 & B & \\
\hline Loanda & Noroeste & $-0,31367$ & $-1,03927$ & $-0,27924$ & 0,11094 & $-0,26235$ & $-0,39878$ & 32,28 & B & \\
\hline Quatiguá & N.Pioneiro & $-0,36826$ & 0,09074 & 0,48806 & $-2,38017$ & $-0,03841$ & $-0,3991$ & 32,27 & B & \\
\hline
\end{tabular}




\begin{tabular}{|c|c|c|c|c|c|c|c|c|c|c|}
\hline r Camargo & N.Central & $-0,67674$ & $-0,92777$ & $-0,20652$ & 0,52578 & $-0,10868$ & $-0,39975$ & 32,25 & B & 321 \\
\hline Andirá & N.Pioneiro & $-0,04542$ & $-0,95827$ & $-0,98670$ & $-0,42433$ & 0,41771 & $-0,40508$ & 32,10 & B & 322 \\
\hline Prado Ferreira & N.Central & $-0,85753$ & $-0,69647$ & $-0,12959$ & 0,58217 & $-0,27394$ & $-0,40729$ & 32,03 & B & 23 \\
\hline Ourizona & N.Central & $-0,64479$ & $-0,85028$ & 0,12810 & 0,21372 & $-0,44709$ & $-0,40775$ & 32,02 & $B$ & 324 \\
\hline Ibiporã & N.Central & 0,16210 & $-1,62372$ & $-0,92427$ & 0,49401 & $-0,20224$ & 862 & 32,00 & D & \\
\hline Mariluz & Noroeste & $-0,74866$ & $-0,40362$ & $-1,14366$ & 0,70269 & 0,02380 & $-0,41384$ & 31,85 & B & \\
\hline Colorado & J.Central & $-0,12128$ & $-0,98376$ & $-0,76454$ & $-0,46006$ & 0,33085 & 45 & 77 & B & \\
\hline Lobato & N.Central & $-0,72903$ & $-1,12123$ & 0,94858 & $-0,36329$ & $-0,15936$ & $-0,41837$ & 31,72 & D & \\
\hline Santa Mônica & Noroeste & $-0,75945$ & $-0,67850$ & 0,20583 & 0,41723 & $-0,89535$ & $-0,41838$ & 31,72 & B & \\
\hline Itan & eiro & $-0,21059$ & $-0,68268$ & 192 & 626 & $-0,4$ & 59 & 31,60 & $\mathrm{~B}$ & \\
\hline Paranaguá & RMC & $-0,51154$ & $-0,20695$ & $-1,17019$ & $-1,60127$ & 1,86803 & $-0,42633$ & 31,49 & 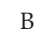 & \\
\hline Japurá & Noroeste & $-0,71868$ & $-0,88487$ & $-0,66547$ & 0,70623 & 0,03858 & $-0,43220$ & 31,32 & B & \\
\hline Castelo & ste & -0 , & $-0,69727$ & $-0,56006$ & $-0,31074$ & 75 & 8 & 3 & B & \\
\hline Terra Rica & Noro & 682 & $-0,68960$ & $-0,11803$ & $-1,70035$ & $-0,4$ & -0, & 31,16 & 3 & \\
\hline Sto Antonio Caiuá & Noroeste & $-0,70780$ & $-0,29950$ & 0,43404 & $-1,60159$ & 0,35485 & $-0,43938$ & 31,12 & B & \\
\hline Pinh & N.Pioneiro & 0,02708 & $-0,02289$ & $-0,09742$ & $-2,00977$ & $-0,93988$ & 69 & 31,08 & B & \\
\hline Indianópolis & Noroeste & $-0,59540$ & $-0,87531$ & 0,82546 & $-0,47242$ & $-0,87893$ & $-0,44399$ & 30,99 & B & \\
\hline Alvorada do Sul & N.Central & $-0,23854$ & $-0,82596$ & $-0,68700$ & $-0,22233$ & $-0,26785$ & $-0,44433$ & 30,98 & B & \\
\hline Foz & Oeste & $-0,16955$ & $-1,33194$ & $-1,58181$ & 0,48107 & 871 & 40 & 30,92 & B & \\
\hline Ribeirão do Pinhal & N.Pioneiro & $-0,05228$ & $-0,52911$ & $-1,38639$ & $-0,18894$ & $-0,51349$ & -0, & 30,71 & B & \\
\hline Florestópolis & N.Central & $-0,58491$ & $-0,41251$ & $-1,17966$ & 0,20973 & $-0,0$ & $-0,4$ & 30,61 & B & \\
\hline Xam & Noroeste & $-0,38315$ & $-0,04823$ & $-0,52517$ & $-1,33419$ & $-0,2$ & $-0,46331$ & 30,44 & B & \\
\hline Japira & N.Pioneiro & $-0,49338$ & $-0,03920$ & 0,29686 & $-1,77669$ & $-0,49870$ & $-0,4$ & 30,42 & B & \\
\hline Cong & N.Pioneiro & $-0,41979$ & $-0,34993$ & $-1,23641$ & 0,24464 & $-0,79673$ & $-0,47928$ & 29,98 & MB & \\
\hline Cidade Gaúcha & Noroeste & $-0,48319$ & $-0,87602$ & $-0,10604$ & $-0,77999$ & 0,13260 & 3080 & 29,94 & $\mathrm{MB}$ & \\
\hline Cafezal do Sul & Noroeste & $-0,56818$ & $-0,84243$ & 0,05609 & $-0,20613$ & $-0,75029$ & $-0,49478$ & 29,54 & $\mathrm{MB}$ & \\
\hline la & Noroeste & $-0,10651$ & $-0,86899$ & $-0,21286$ & $-1,01777$ & $-0,57800$ & $-0,49519$ & 29,53 & MB & \\
\hline o Itararé & N.Pio & $-0,33771$ & 0,27369 & $-0,44371$ & $-1,96575$ & $-0,60199$ & $-0,50$ & 29,29 & $\mathrm{MB}$ & \\
\hline Porto Rico & Noroeste & $-0,58652$ & $-0,70016$ & 1,07054 & $-1,87367$ & $-0,27811$ & $-0,50619$ & 29,22 & MB & \\
\hline Atalaia & N.Central & $-0,65401$ & $-0,87689$ & $-0,63516$ & 0,33593 & $-0,37003$ & $-0,51190$ & 29,06 & MB & \\
\hline Ivaté & Noroeste & $-0,64157$ & $-0,70501$ & $-0,18675$ & $-0,26506$ & $-0,55807$ & $-0,51324$ & 29,02 & $\mathrm{MB}$ & \\
\hline Lupionópolis & N.Central & $-0,86166$ & $-0,64257$ & $-0,60528$ & 0,08643 & 0,02706 & $-0,51373$ & 29,00 & MB & \\
\hline Tamboara & Noroeste & $-0,67227$ & $-0,76488$ & $-0,21983$ & $-0,27433$ & $-0,34$ & $-0,51732$ & 28 & $\mathrm{MB}$ & \\
\hline $\begin{array}{l}\text { S. Sebastião } \\
\text { Amoreir }\end{array}$ & N.Pioneiro & $-0,30788$ & $-0,98610$ & $-0,82600$ & $-0,24627$ & $-0,21405$ & $-0,52313$ & 28,74 & $\mathrm{MB}$ & \\
\hline Uniflor & N.Central & $-0,78223$ & $-0,67227$ & $-0,36902$ & $-0,01384$ & $-0,43613$ & $-0,52$ & 28,59 & MB & \\
\hline São Tomé & Noroeste & $-0,64754$ & $-0,97649$ & 0,19854 & $-0,48737$ & $-0,40588$ & $-0,52976$ & 28,55 & $\mathrm{MB}$ & \\
\hline Munhoz de Mello & N.Central & $-0,88077$ & $-0,92567$ & $-0,29642$ & 0,45721 & $-0,41294$ & $-0,53020$ & 28,54 & $\mathrm{MB}$ & \\
\hline Jaboti & N.Pioneiro & $-0,44177$ & $-0,08418$ & $-0,09562$ & $-1,8797$ & $-0,46133$ & $-0,53169$ & 28,49 & $\mathrm{MB}$ & \\
\hline Jussara & Noroeste & $-0,66666$ & $-1,24262$ & $-0,11258$ & 0,19076 & $-0,37475$ & $-0,53691$ & 28,34 & $\mathrm{MB}$ & \\
\hline Marilena & Noroeste & $-0,36966$ & $-0,54639$ & $-0,50237$ & $-1,14937$ & $-0,24974$ & $-0,53756$ & 28,33 & MB & \\
\hline Nova Londrina & Noroeste & $-0,46215$ & $-1,00007$ & $-0,39651$ & $-1,49940$ & 1,05967 & $-0,54655$ & 28,07 & $\mathrm{MB}$ & \\
\hline Nova Fátima & N.Pioneiro & $-0,36678$ & $-0,92134$ & $-0,87965$ & $-0,31436$ & $-0,23304$ & $-0,54989$ & 27,97 & $\mathrm{MB}$ & \\
\hline Paiçandu & N.Central & $-0,67582$ & $-1,42224$ & $-0,97095$ & 0,70967 & 0,28044 & $-0,55786$ & 27,75 & $\mathrm{MB}$ & \\
\hline
\end{tabular}




\begin{tabular}{|c|c|c|c|c|c|c|c|c|c|c|}
\hline Nova Aliança Ivaí & Noroeste & $-0,61365$ & $-0,90081$ & 1,46766 & $-1,99653$ & $-0,63848$ & $-0,55959$ & 27,70 & MB & 364 \\
\hline Paranapoema & Noroeste & $-0,84144$ & $-0,77775$ & $-0,25237$ & $-0,32376$ & $-0,19364$ & $-0,57128$ & 27,37 & MB & 365 \\
\hline Uraí & N.Pioneiro & $-0,05801$ & $-0,84323$ & $-1,36306$ & $-0,40016$ & $-0,70405$ & $-0,57879$ & 27,15 & MB & 66 \\
\hline Pérola & Noroeste & $-0,11807$ & $-0,64038$ & $-0,30570$ & $-1,94709$ & $-0,35353$ & $-0,57978$ & 27,12 & MB & 367 \\
\hline acema do Oeste & Oeste & $-0,94231$ & $-1,16628$ & $-0,51217$ & 1,01270 & $-0,63941$ & $-0,58118$ & 27,08 & MB & 68 \\
\hline N.Sra. das Graças & N.Central & $-0,80914$ & $-0,95309$ & $-0,28368$ & $-0,06119$ & $-0,36614$ & 533 & 26,97 & MB & 59 \\
\hline $\begin{array}{l}\text { Sto. Antonio } \\
\text { Paraíso }\end{array}$ & N.Pioneiro & $-0,85720$ & $-0,89718$ & $-0,50740$ & 0,49010 & $-0,7$ & -0 , & 26,95 & MB & \\
\hline $\begin{array}{l}\text { Diamante do } \\
\text { Norte }\end{array}$ & Noroeste & $-0,61659$ & $-0,70779$ & $-1,04357$ & $-0,30305$ & $-0,03957$ & 633 & 26,94 & MB & 371 \\
\hline Ivão & N.Pioneiro & $-0,71648$ & $-0,61303$ & $-1,44297$ & 0,35297 & $-0,24635$ & 639 & 26,94 & MB & 372 \\
\hline Figueira & N.Pioneiro & $-0,78500$ & $-0,30248$ & $-1,22425$ & $-0,17282$ & $-0,26837$ & $-0,58865$ & 26,87 & MB & 373 \\
\hline S.Jorge Patrocinio & Noroeste & $-0,08913$ & $-0,51267$ & $-0,86966$ & $-1,46000$ & $-0,62067$ & $-0,58977$ & 26,84 & MB & 74 \\
\hline Guairaçá & Noroeste & $-0,36654$ & $-0,91847$ & 0,49837 & $-1,74794$ & $-0,57665$ & 161 & 26,79 & MB & 375 \\
\hline Santa Amélia & N.Pioneiro & $-0,67535$ & $-0,42142$ & $-1,64151$ & 0,33015 & $-0,48126$ & $-0,59421$ & 26,71 & MB & 376 \\
\hline Esperança Nova & Noroeste & $-0,65668$ & $-0,25259$ & 0,36078 & $-1,67133$ & $-0,95536$ & $-0,59588$ & 26,67 & MB & 377 \\
\hline Tapejara & Noroeste & $-0,27730$ & $-1,00602$ & $-0,49922$ & $-0,82104$ & $-0,57266$ & 816 & 26,60 & MB & 378 \\
\hline Santa Fé & N.Central & $-0,83348$ & $-1,16942$ & $-1,24539$ & 0,77770 & 0,11568 & $-0,60784$ & 26,32 & MB & 379 \\
\hline Perobal & Noroeste & $-0,66376$ & $-0,78491$ & $-0,32472$ & $-0,37623$ & $-0,80575$ & $-0,60880$ & 26,30 & MB & 380 \\
\hline Alto Paraná & Noroeste & 0,06679 & $-1,03658$ & $-0,57999$ & $-1,73488$ & $-0,2$ & $-0,61103$ & 26,23 & MB & 381 \\
\hline Sta. Izabel do Ivaí & Noroeste & $-0,09983$ & $-0,92864$ & $-0,01880$ & $-1,85197$ & $-0,65029$ & $-0,61378$ & 26,16 & MB & 382 \\
\hline anco & N.Central & $-0,70423$ & $-0,95556$ & $-0,33992$ & $-0,59400$ & $-0,20799$ & $-0,62344$ & 25,88 & MB & 38 \\
\hline Planaltina do PR & Noroeste & $-0,44512$ & $-0,76180$ & 0,47970 & $-1,87550$ & $-0,74303$ & $-0,62604$ & 25,81 & MB & 384 \\
\hline $\begin{array}{l}\text { Nova América } \\
\text { Coli }\end{array}$ & N.Pioneiro & $-0,64827$ & $-0,72936$ & $-0,96752$ & $-0,10690$ & $-0,70017$ & $-0,64028$ & 25,40 & MB & 38 \\
\hline Quatro Barras & RMC & $-0,59049$ & $-0,45360$ & $-0,57818$ & $-1,87643$ & 0,26832 & $-0,65222$ & 25,06 & MB & 386 \\
\hline Rancho Alegre & N.Pioneiro & $-0,62917$ & $-1,13036$ & $-0,77620$ & $-0,06308$ & $-0,46921$ & $-0,65779$ & 24,90 & MB & 387 \\
\hline Sarandi & N.Central & $-0,88481$ & $-1,85753$ & $-1,79903$ & 1,16448 & 1,33434 & $-0,65901$ & 24,87 & MB & 388 \\
\hline S.Pedro do PR & Noroeste & $-0,57149$ & $-0,76620$ & 0,41159 & $-1,79964$ & $-0,89168$ & $-0,68679$ & 24,08 & MB & 389 \\
\hline Antonina & RMC & $-0,34796$ & $-0,07920$ & $-1,31405$ & $-1,74223$ & $-0,58392$ & $-0,68023$ & 23,98 & MB & 390 \\
\hline Flórida & N.Central & $-0,86435$ & $-1,31901$ & $-0,27863$ & $-0,25533$ & $-0,20121$ & $-0,69517$ & 23,84 & MB & 391 \\
\hline ova Olimpia & Noroeste & $-0,54769$ & $-1,05927$ & 0,20223 & $-1,83640$ & $-0,28866$ & $-0,71008$ & 23,42 & MB & , \\
\hline S. João do Caiuá & Noroeste & $-0,46506$ & $-0,84047$ & $-0,24823$ & $-1,77178$ & $-0,47340$ & $-0,71891$ & 23,16 & MB & 393 \\
\hline Guaratuba & RMC & $-0,04094$ & $-0,96756$ & $-0,96790$ & $-1,89971$ & $-0,68678$ & $-0,76686$ & 21,80 & MB & 394 \\
\hline Jataizinho & N.Pioneiro & $-0,44802$ & $-1,48407$ & $-1,04636$ & $-0,21255$ & $-0,72549$ & $-0,77537$ & 21,56 & MB & נJ \\
\hline Itaúna do Sul & Noroeste & $-0,63824$ & $-0,65640$ & $-0,58761$ & $-1,68518$ & $-0,58198$ & $-0,79026$ & 21,13 & MB & 396 \\
\hline Nova Sta Bárbara & N. Pioneiro & $-0,72823$ & $-0,99554$ & $-1,25127$ & 0,01394 & $-1,00202$ & $-0,79117$ & 21,11 & MB & 39 \\
\hline Matinhos & RMC & $-0,97239$ & $-1,34180$ & $-1,71838$ & $-1,91332$ & $-0,11174$ & $-1,21680$ & 8,99 & MMB & 398 \\
\hline Pontal do Paraná & RMC & $-0,59732$ & $-2,21111$ & $-1,75837$ & $-2,20388$ & $-1,68751$ & $-1,53273$ & 0,00 & MMB & 399 \\
\hline
\end{tabular}

\section{Recebido em junho de 2006 e revisto em novembro de 2006}

RER, Rio de Janeiro, vol. 45, no 02, p. 329-365, abr/jun 2007 - Impressa em abril 2007 